\title{
High-thermally conductive AIN-based microwave attenuating composite ceramics with spherical graphite as attenuating agent
}

\author{
Xia FANG ${ }^{a, b}$, Lei JIANG ${ }^{a, b}$, Limei PAN ${ }^{a, b}$, Shuang YIN ${ }^{a, b}$, Tai QIU ${ }^{a, b}$, Jian YANG ${ }^{a, b, *}$ \\ ${ }^{a}$ Jiangsu Collaborative Innovation Center for Advanced Inorganic Function Composites, Nanjing 211816, China \\ ${ }^{b}$ College of Materials Science and Engineering, Nanjing Tech University, Nanjing 211816, China
}

Received: August 21, 2020; Revised: November 24, 2020; Accepted: November 27, 2020

(c) The Author(s) 2020.

\begin{abstract}
High-thermally conductive AlN-based microwave attenuating composite ceramics with spherical graphite $(\mathrm{SG})$ as the attenuating agent were fabricated through hot-pressing sintering. The SG maintains its three-dimensional (3D) morphology within the sintered bodies, which considerably impedes the sintering of the composites to some extent but slightly influences on the growth of AlN grains. The addition of SG reduces the strength of the composites, but provides a moderate toughening effect at the optimal addition amount (3.8 MPa $\cdot \mathrm{m}^{1 / 2}$ at $\left.4 \mathrm{wt} \% \mathrm{SG}\right)$. Benefiting from the low anisotropy, high thermal conductivity, and the 3D morphology of $\mathrm{SG}$, the composites exhibit a relatively higher thermal conductivity $\left(76.82 \mathrm{~W} \cdot \mathrm{m}^{-1} \cdot \mathrm{K}^{-1}\right.$ at $\left.10 \mathrm{wt} \% \mathrm{SG}\right)$ compared with composites added with non-spherical attenuating agent. The dielectric constant and loss $(8.2-12.4 \mathrm{GHz})$ increase remarkably as the amount of SG added increases up to $8 \mathrm{wt} \%$, revealing that the incorporation of SG improves the dielectric property of the composite. The composite with $7 \mathrm{wt} \% \mathrm{SG}$ exhibits the best absorption performance with a minimum reflection loss of $-13.9 \mathrm{~dB}$ at $12.4 \mathrm{GHz}$ and an effective absorbing bandwidth of $0.87 \mathrm{GHz}$. The excellent overall properties of the SG/AlN microwave attenuating composites render them as a promising material for various applications. Moreover, SG has a great potential as an attenuating agent for microwave attenuating composites due to its strong attenuation upon integration, high thermal conductivity, and low anisotropy.
\end{abstract}

Keywords: spherical graphite (SG); aluminum nitride; thermal conductivity; dielectric property; microwave absorption

\section{Introduction}

A microwave attenuating material is a vacuum electronic material which is crucial in radars, early-warning aircrafts, and microwave measurement systems [1-6]. It absorbs electromagnetic waves within specific frequency bands and converts them into heat energy for the inhibition of

* Corresponding author.

E-mail: yangjian1976@163.com sideband oscillation, broadening of bandwidth, and improving electromagnetic matching during operations. With the fast development of vacuum electronic devices into extreme application conditions such as high frequency, high power, and high temperature, it is indispensable for microwave attenuating materials to have a high thermal conductivity, in addition to an excellent microwave absorption capability, to enable them to conduct the heat energy efficiently and avoid damage to working devices caused by high temperature. 
As a result of their outstanding characteristics such as high thermal conductivity, good mechanical properties, high-temperature stability, and moderate dielectric constants, ceramic-based composite attenuating materials, such as $\mathrm{BeO}, \mathrm{MgO}, \mathrm{Al}_{2} \mathrm{O}_{3}$, and $\mathrm{AlN}$ matrix composite ceramics, have been one of the extensive application for attenuation materials [1], wherein AIN has been regarded as the most advantageous attenuating ceramic matrix by virtue of its high thermal conductivity $\left(320 \mathrm{~W} \cdot \mathrm{m}^{-1} \cdot \mathrm{K}^{-1}\right)$, high strength, high insulation, non-toxicity, and low out-gassing under a vacuum environment [1,2]. The preparation of AlN-based microwave attenuating composite ceramics generally involves the introduction of metal conductors (W and Mo), semiconductors ( $\mathrm{SiC}$ and $\mathrm{TiO}_{2}$ ), or carbonaceous materials (graphite, carbon black, graphene, and carbon nanotubes) to improve the dielectric loss of the AlN-based composites, and enhance their microwave attenuation $[3,4]$. However, the thermal conductivity of AlN ceramics is highly sensitive to the introduction of a second phase, and all the pores, interfaces, grain boundary impurities, and crystal defects resulting from the addition of the attenuating agent greatly reduces the thermal conductivity of AlN-based composites [7-9].

To improve the thermal conductivity of AlN-based attenuating composites, highly thermally conductive metal attenuating agents have been employed. However, the inhomogeneous microstructure induced by the mismatching density between the AlN matrix and the metallic materials inevitably affects the thermal stability of the composite material. The wide band gap semiconductor $\mathrm{SiC}$ has been widely applied as an attenuating agent for preparing AlN-based attenuating composite ceramics. However, the addition of $\mathrm{SiC}$ not only increases the heterogeneous interface, but also generates a $\mathrm{SiC} / \mathrm{AlN}$ solid solution. As a result, the SiC/AlN composites develop a large interface, high thermal resistance, and numerous crystal defects, which would cause severe phonon scattering and the deterioration of thermal conductivity of the SiC/AIN composite attenuating ceramics $[1,10,11]$.

In recent years, the lightweight carbonaceous nanomaterials with high electrical and thermal conductivity such as graphene and carbon nanotubes (CNTs), have been considered as promising attenuating agents for the preparation of ceramic matrix microwave attenuating composite materials [12-19]. Several studies have found that a small amount of incorporated graphene and CNTs greatly improves electrical conductivity and dielectric properties of AlN-based composite materials [7-9], making them potentially suitable attenuating agents for the preparation of AlN-based composite materials. Liang et al. [20] reported that, within the frequency range of $26.5-40.0 \mathrm{GHz}$, both the dielectric constant and dielectric loss of AlN/CNT composites increased significantly as the CNT content increased, and a high dielectric loss tangent $\left(\tan \delta=\varepsilon^{\prime \prime} / \varepsilon^{\prime}\right)$ of $0.1-0.61$ was achieved at $5 \mathrm{vol} \%$ CNT. Nonetheless, as CNTs have a very large specific surface area and a hollow tubular structure, they can adsorb a large amount of gas and may undergo out-gassing under a high vacuum environment, thus limiting their application in preparing vacuum electronic materials $[21,22]$. Graphene has an ultra-high thermal conductivity along the in-plane direction, whereas its layered structure readily produces a large heterogeneous interface between AlN matrix and graphene, which greatly reduces the thermal conductivity of AlN/graphene composite materials [7,8]. Yin et al. [23] reported that the thermal conductivity of graphene platelets/AlN composites sharply decreased from 58.21 to 13.84 $\mathrm{W} \cdot \mathrm{m}^{-1} \cdot \mathrm{K}^{-1}$ as the graphene content increased from 0 to $9.5 \mathrm{wt} \%$. In addition, one/two-dimensional (1D/2D) carbonaceous nanomaterials are generally anisotropic $[7,24]$, which is detrimental to the uniform heat dissipation of the material. Although various potential attenuating agents, such as metal conductors, semiconductors, and carbonaceous materials, have been studied, none of them are suitable for the preparation of a highly thermally conductive AlN-based attenuating composite materials with no anisotropy. To improve the work reliability of microwave attenuating materials in future work, it is important to exploit an attenuating agent that can satisfy the demand of combined high thermal conductivity, strong attenuation, and low anisotropy.

Among the previously reported attenuating agents, graphite is a traditional carbonaceous material with an excellent electrical conductivity $\left(\sim 10^{6} \mathrm{~S} / \mathrm{m}\right)$, thermal conductivity $\left(\sim 2200 \mathrm{~W} \cdot \mathrm{m}^{-1} \cdot \mathrm{K}^{-1}\right)$ [25], high thermal stability, and low cost, and hence, it is considered as a promising material for the preparation of materials with strong attenuation [26-34]. Historical studies have shown that the introduction of a small amount of graphite can improve the dielectric and microwave absorption properties of the composites incorporated with graphite [29-34]. Torğut et al. [32] found that the incorporation of graphite into a polymer matrix 
significantly enhanced the polarization loss of the composites, and the real dielectric constant $\varepsilon^{\prime}$ value of the $10 \mathrm{wt} \%$ composite was 80.5 , higher than that of the monolithic polymer material. Sun et al. [33] fabricated $\mathrm{SiC} /$ graphite composites based on a porous $\mathrm{SiC}$ matrix, and they found that introducing graphite from 1 to $7 \mathrm{wt} \%$ increased the electrical conductivity of the composite by five orders of magnitude. Moreover, the incorporation of graphite resulted in the multiple reflections of the electromagnetic waves inside the material, improving the electromagnetic shielding performance of the SiC/graphite composite. Zhang et al. [34] observed that when the graphite/geopolymer ratio was 12 , the minimum reflection loss $\left(R L_{\min }\right)$ of the graphite/geopolymer composite reached $-65 \mathrm{~dB}$ at a frequency range of $2-18 \mathrm{GHz}$ and at a thickness of $4.15 \mathrm{~mm}$. However, the application of graphite in preparing AlN-based microwave attenuating composite material has not been reported in detail until now. Moreover, in all of the reports on composite absorption materials filled with graphite, the flake graphite is dominantly employed. Coinciding with its 2D structure of 2D materials, the high aspect ratio of flake graphite can also result in numerous heterogeneous interfaces inside the matrix, just like graphene, thereby limiting the improvement of the thermal conductivity of the composite. Moreover, the composites filled with 2D flake graphite also suffer from the anisotropic thermal, electricity, and dielectric properties [25,35-38]. For example, Li et al. [38] employed the squeeze casting method to fabricate graphite flakes/Al composites and found that as the graphite content varied from 40 to $70 \mathrm{vol} \%$, the thermal conductivity of the composites increased from 544 to $714 \mathrm{~W} \cdot \mathrm{m}^{-1} \cdot \mathrm{K}^{-1}$ in the direction parallel to the plane of the graphite layers but decreased from 104 to $31 \mathrm{~W} \cdot \mathrm{m}^{-1} \cdot \mathrm{K}^{-1}$ in the direction perpendicular to the plane of the graphite layers, resulting from the high interfacial thermal resistance, low thermal conductivity $\left(6 \mathrm{~W} \cdot \mathrm{m}^{-1} \cdot \mathrm{K}^{-1}\right)$ and the anisotropy caused by the addition of flake graphite. This suggests that there is a great limitation on the preparation of high-performance microwave attenuating materials with high thermal conductivity and low anisotropy when flake graphite is employed as the attenuating agent, and to the best of our knowledge, which remains a great challenge to date.

In this work, considering the high electrical and thermal conductivities and microwave absorption property of graphite, spherical graphite, instead of the traditional flake graphite, was chosen as the attenuating agent in the preparation of AlN-based composite ceramics with strong attenuation, high thermal conductivity, and low anisotropy. SG is a granulated form of graphite, which not only enjoys excellent thermal and electrical properties similar to flake graphite, but also has a low anisotropy as opposed to flake graphite. More importantly, the spherical morphology of SG results in its relatively small aspect ratio, which can potentially reduce the heterogeneous interfaces between the graphite particles and the AlN matrix and their adverse effect of interfacial thermal resistance on the thermal conductivity of the composites. Owing to its high electrical conductivity, low specific surface area, chemical resistance, high crystallinity, and high theoretical lithium insertion capacity, SG is widely utilized as a substitute for the traditional flake graphite for the preparation of the battery negative electrodes $[39,40]$. However, there are few reports on the preparation of ceramic matrix microwave attenuating composites filled with spherical graphite.

To explore the potential and feasibility of employing SG as a highly effective attenuating agent for the preparation of AlN-based microwave attenuating composite materials, the effects of the mass fraction of SG on the sintering, mechanical, thermal, dielectric, and absorption properties of the SG/AIN composites were systematically studied. The obtained SG/AIN composites exhibited a low anisotropy, excellent thermal conductivity, and strong dielectric loss and absorption ability, which demonstrated their potential as high-performance attenuation materials for future applications after further optimization.

\section{Experimental}

\section{1 Preparation of SG/AIN composite ceramics}

Commercial AlN (1-2 $\mu \mathrm{m}$, Liaoning Desheng Special Ceramics Manufacturing Co., Ltd., China), $\mathrm{Y}_{2} \mathrm{O}_{3}\left(d_{50}=\right.$ $7 \mu \mathrm{m}$, purity $99.95 \%$, Shanghai Yuelong Chemical Factory, China), and SG ( $d_{50}=6 \mu \mathrm{m}$, Qingdao Haida Graphite Co., Ltd., China) were used as the raw materials. The microscopic morphology of the spherical graphite is depicted in Fig. 1. The SG particles are oval, and they have a significant difference from the layer structure of flake graphite.

The amount of the sintering aid $\mathrm{Y}_{2} \mathrm{O}_{3}$ was fixed at $4 \mathrm{wt} \%$, and the $\mathrm{SG}$ content was varied from 0 to 


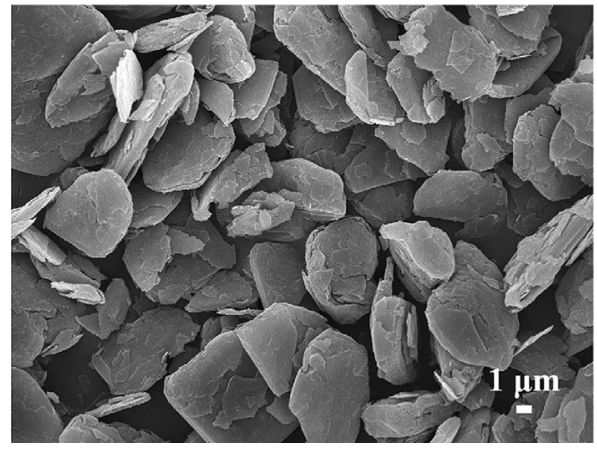

Fig. 1 Micromorphology of spherical graphite raw material.

$16 \mathrm{wt} \%$. The preparation process of the SG/AlN composites is schematically shown in Fig. 2. First, the AlN and $\mathrm{Y}_{2} \mathrm{O}_{3}$ powders were ball-milled for $4 \mathrm{~h}$ in a planetary ball mill at a rotating speed of $160 \mathrm{rpm}$. Thereafter, they were dried at $80{ }^{\circ} \mathrm{C}$ for $24 \mathrm{~h}$, ground, and then sieved through a size of 60 mesh. Varying amounts of $\mathrm{SG}$ powders were mixed with the $\mathrm{AlN}-\mathrm{Y}_{2} \mathrm{O}_{3}$ composite powders in anhydrous ethanol, and the mixture was combined under magnetic stirring (S10-3, Shanghai Sile Equipment Co., Ltd., China) and mechanical stirring (JJ-1, Jiangyin Poly Research Equipment Co., Ltd., China) for $2.5 \mathrm{~h}$ at $750 \mathrm{rpm}$. The mixture was dried at $120{ }^{\circ} \mathrm{C}$ for $8 \mathrm{~h}$, and the resultant powders were sieved through a size of 60 mesh. The as-prepared composite powders with different SG contents were loaded into graphite molds and then hot-pressing sintered under a nitrogen $\left(\mathrm{N}_{2}\right)$ atmosphere, with a sintering temperature of $1900{ }^{\circ} \mathrm{C}$, uniaxial pressure of $25 \mathrm{MPa}$, and holding time of $1 \mathrm{~h}$. Finally, the as-sintered samples were cooled to room temperature and then taken out of their molds.

\section{2 Testing and characterization}

The phase composition of the as-prepared SG/AIN composites was detected using X-ray diffraction (XRD, Smartlab, Japan) analysis. The X-ray photoelectron spectroscopy (XPS, AXIS Ultra DLD, Kratos, UK) was carried out to determine the chemical composition of the surface of the sample. The bulk density $\left(\rho_{\mathrm{b}}\right)$ of the sintered sample was measured by Archimedes method, and then the bulk density of the sample was divided by the corresponding theoretical density $\left(\rho_{\mathrm{t}}\right)$ to obtain the relative density $\left(\rho_{\mathrm{r}}\right)$, i.e., $\rho_{\mathrm{r}}=\rho_{\mathrm{b}} / \rho_{\mathrm{t}}$, wherein the theoretical density of a fully dense composite was calculated in accordance with the rule of mixtures, assuming the densities of $3.26 \mathrm{~g} \cdot \mathrm{cm}^{-3}$ for AlN, $5.01 \mathrm{~g} \cdot \mathrm{cm}^{-3}$ for $\mathrm{Y}_{2} \mathrm{O}_{3}$, and $2.25 \mathrm{~g} \cdot \mathrm{cm}^{-3}$ for SG respectively. The flexural strength of the sample with dimensions of $4 \mathrm{~mm} \times 3 \mathrm{~mm} \times 36 \mathrm{~mm}$ was tested using the three-point bending method at a loading rate of $0.5 \mathrm{~mm} \cdot \mathrm{min}^{-1}$. To test the fracture toughness of the sample, the single edge notch beam method was carried out at a loading rate of $0.05 \mathrm{~mm} \cdot \mathrm{min}^{-1}$ for a sample with dimensions of $4 \mathrm{~mm} \times 2 \mathrm{~mm} \times 30 \mathrm{~mm}$, with a groove depth of $2 \mathrm{~mm}$ and width of $0.1 \mathrm{~mm}$. A field emission scanning electron microscope (FESEM, SU8010, Hitachi, Japan) equipped with an energy dispersive system (EDS) was used to analyze the fracture morphology and chemical composition of the sample. The thermal diffusivity $\alpha$ of the sample $(\Phi 12.7 \mathrm{~mm} \times$ $2 \mathrm{~mm}$ ) was determined using a laser thermal conductivity meter (LFA447, Netzsch, Germany) under the protection
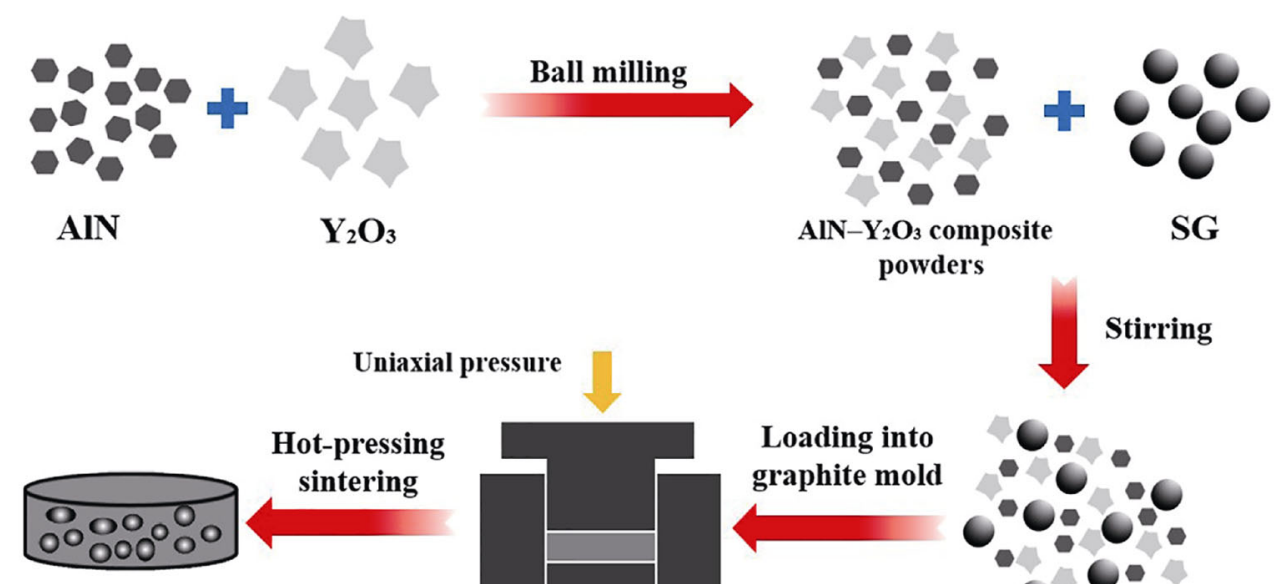

SG/AIN sintered sample

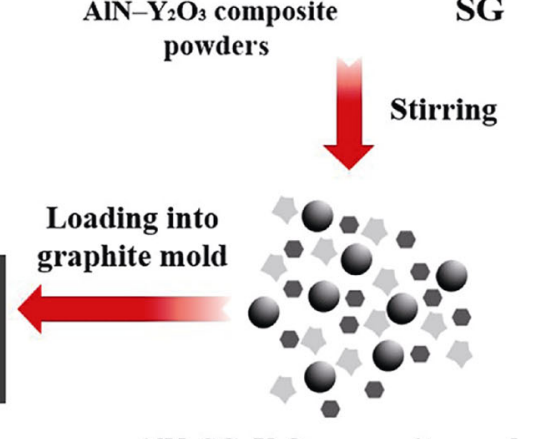

AlN-SG- $\mathrm{Y}_{2} \mathrm{O}_{3}$ composite powders

Fig. 2 Schematic of the preparation process for fabricating the SG/AIN composites. 
of helium atmosphere, and the thermal conductivity $\lambda$ of the sample was calculated by Eq. (1) [41]:

$$
\lambda=\alpha \times C_{\mathrm{p}} \times \rho
$$

where $\rho$ is the bulk density of the sample and $C_{\mathrm{p}}$ is the heat capacity. Each sample subjected to thermal analysis was tested for three times, and the mean value was calculated. To investigate the dielectric properties and microwave absorption properties of the samples, the waveguide method with a vector network analyzer was used to test the electromagnetic parameters of the sample $(22.86 \mathrm{~mm} \times 10.16 \mathrm{~mm} \times 2.5 \mathrm{~mm})$ in the X-band (8.2-12.4 GHz). The alternating-current (AC) impedance $\left(1-10^{6} \mathrm{~Hz}\right)$ of the sample was tested by electrochemical stations (CHI760E, China).

\section{Results and discussion}

\section{1 Phase composition}

The XRD patterns of the as-sintered SG/AIN composites with various SG contents are presented in Fig. 3(a). The main phases in the monolithic AlN ceramic are AlN and $\mathrm{Al}_{5} \mathrm{Y}_{3} \mathrm{O}_{12}$, while the main phases in the $\mathrm{SG} / \mathrm{AlN}$ composites are $\mathrm{AlN}$, carbon $(\mathrm{C})$, and $\mathrm{Al}_{5} \mathrm{Y}_{3} \mathrm{O}_{12}$. No other carbon-containing compound was detected, illustrating that SG did not react with any other phases during the sintering process. The XRD patterns of the SG raw material and SG/AlN composites with various SG contents within a small $2 \theta$ angle range are shown in Fig. 3(b). Visibly, the diffraction peak of $\mathrm{C}$ becomes stronger as the SG content increases, and the position of the $\mathrm{C}$ diffraction peak in the composite material shows no significant change with that in the SG raw material. This indicates that SG maintains as its original

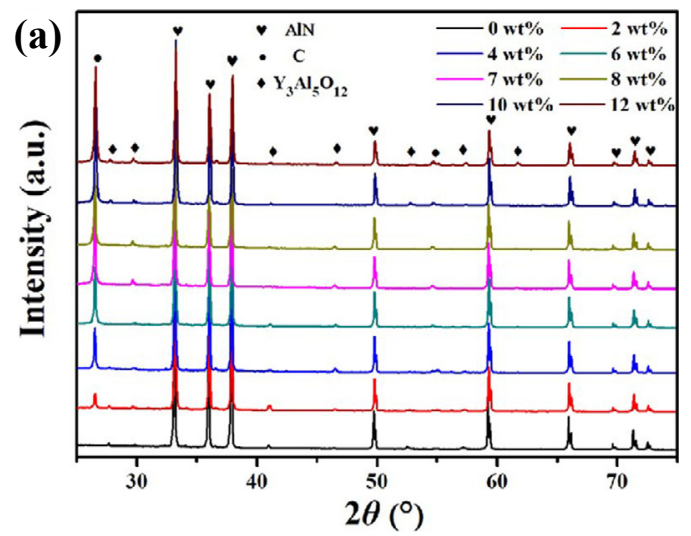

graphitic structure in the sintered sample. The existence of $\mathrm{Y}_{3} \mathrm{Al}_{5} \mathrm{O}_{12}$ is ascribed to be the reaction between $\mathrm{Y}_{2} \mathrm{O}_{3}$ and $\mathrm{Al}_{2} \mathrm{O}_{3}$ that exists on the surface of $\mathrm{AlN}$, which not only promotes the liquid phase sintering of the AlN-based composite under a relatively low temperature, but also effectively removes the oxygen impurities in the lattice of AlN, thereby enhancing the thermal conductivity of the AlN-based composite ceramics $[42,43]$.

To further identify the chemical forms and interactions of each element in the SG/AIN composite, the XPS survey spectra of the $4 \mathrm{wt} \%$ composite were obtained and presented in Fig. 4. Several typical peaks for Al 2p, $\mathrm{C} 1 \mathrm{~s}, \mathrm{~N} 1 \mathrm{~s}, \mathrm{Y} 3 \mathrm{~d}$, and $\mathrm{O} 1 \mathrm{~s}$ can be clearly identified in Fig. 4(a). In the XPS spectra of Al 2p, as shown in Fig. 4(b), the intensity of peaks at 73.65 and $74.73 \mathrm{eV}$ correspond to the $\mathrm{Al}-\mathrm{N}$ and $\mathrm{Al}-\mathrm{O}$ bonds, respectively [44]. It can be inferred that the $\mathrm{Y}_{3} \mathrm{Al}_{5} \mathrm{O}_{12}$ is responsible for the formation of Al-O. The $\mathrm{N}$ element mainly exists in the form of the $\mathrm{N}-\mathrm{Al}$ bond $(396.7 \mathrm{eV})$ in the sintered body [44]. In addition, the two slight and minor peaks appear at 397.5 and $399.8 \mathrm{eV}$ correspond to pyridinic $\mathrm{N}[45,46]$ and pyrrolic $\mathrm{N}$ [47], respectively. This may be attributed to that a few $\mathrm{C}$ atoms which were doped into the AlN lattice and replaced the $\mathrm{N}$ atoms [48]. The $\mathrm{C} 1 \mathrm{~s}$ spectrum can be divided into $\mathrm{C}-\mathrm{C}(284.8 \mathrm{eV})[45,49], \mathrm{C}-\mathrm{O}(286.1 \mathrm{eV})$, and $\mathrm{C}=\mathrm{O}$ $(288.7 \mathrm{eV})$ bonds [50]. The presence of $\mathrm{C}-\mathrm{O}$ bonds may be due to a small amount of oxidation of graphite during the drying process. Nevertheless, no other C bonds were found in the composite, further confirming that SG still maintained its original graphitic structure within the sintered body, and no $\mathrm{N}$ doping of the SG occurred even after sintering under a $\mathrm{N}_{2}$ protective atmosphere.

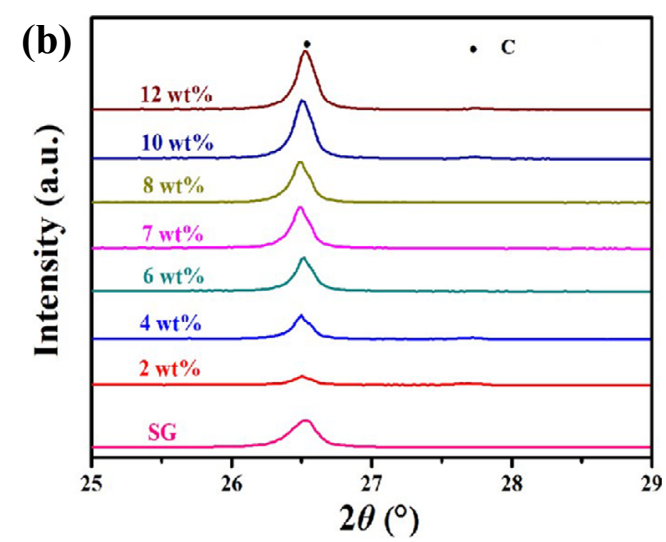

Fig. 3 (a) XRD patterns of SG/AlN composites with different SG contents and (b) XRD patterns of SG raw powders and $\mathrm{SG} / \mathrm{AlN}$ composites with different SG contents at $25^{\circ}-29^{\circ}$. 

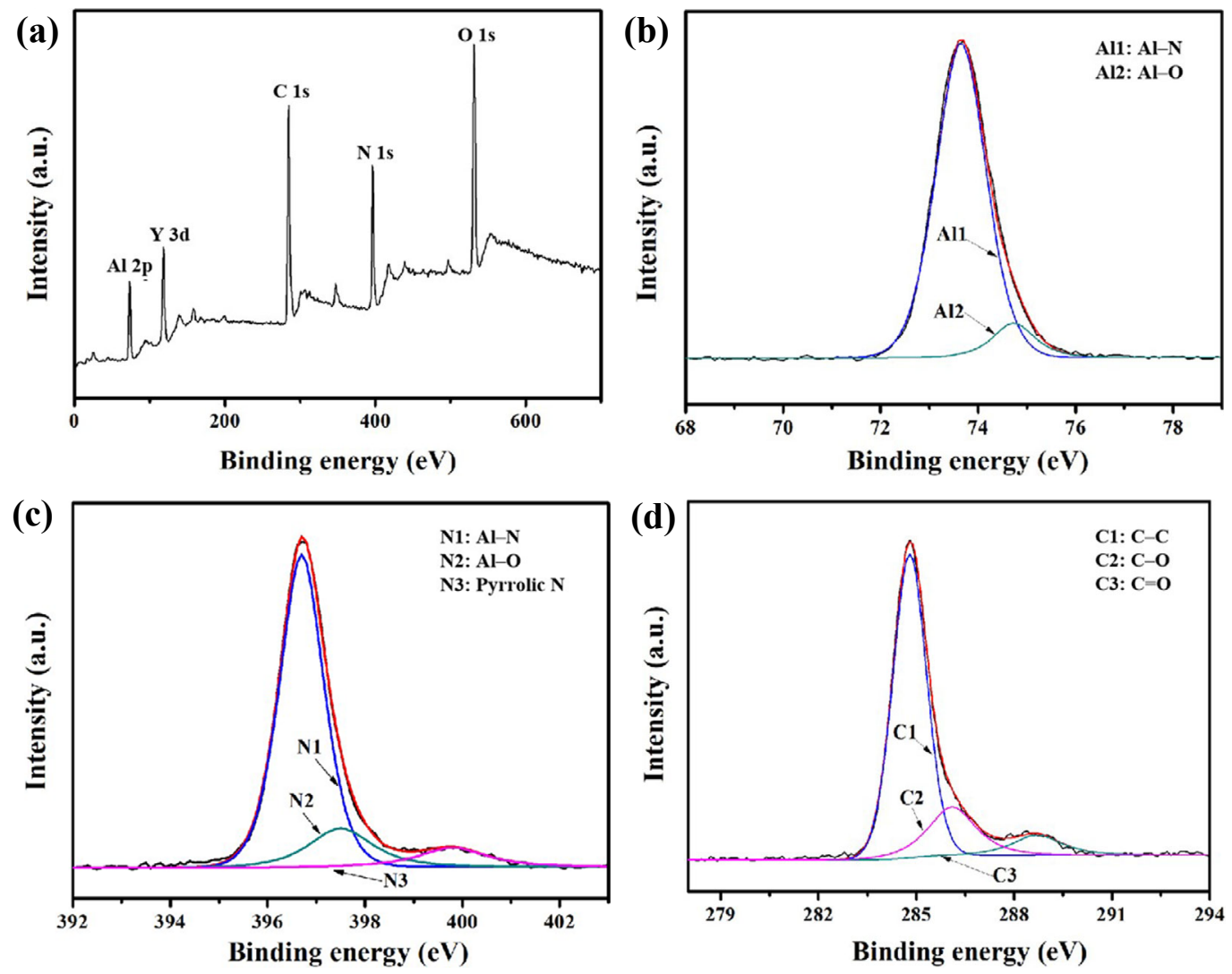

Fig. 4 (a) XPS survey spectra of $4 \mathrm{wt} \%$ composite and (b-d) the spectra of $\mathrm{Al} 2 \mathrm{p}, \mathrm{N} 1 \mathrm{~s}$, and C $1 \mathrm{~s}$, respectively.

\section{2 Sintering properties and microstructure}

The bulk density and relative density of the SG/AlN composites with varying SG contents are shown in Fig. 5. As the SG content increases from 0 to $16 \mathrm{wt} \%$, the bulk density and relative density of the composites decrease monotonously from 3.30 to $3.00 \mathrm{~g} \cdot \mathrm{cm}^{-3}$ and $99.50 \%$ to $96.73 \%$, respectively. The descend of relative density indicates that the SG addition significantly

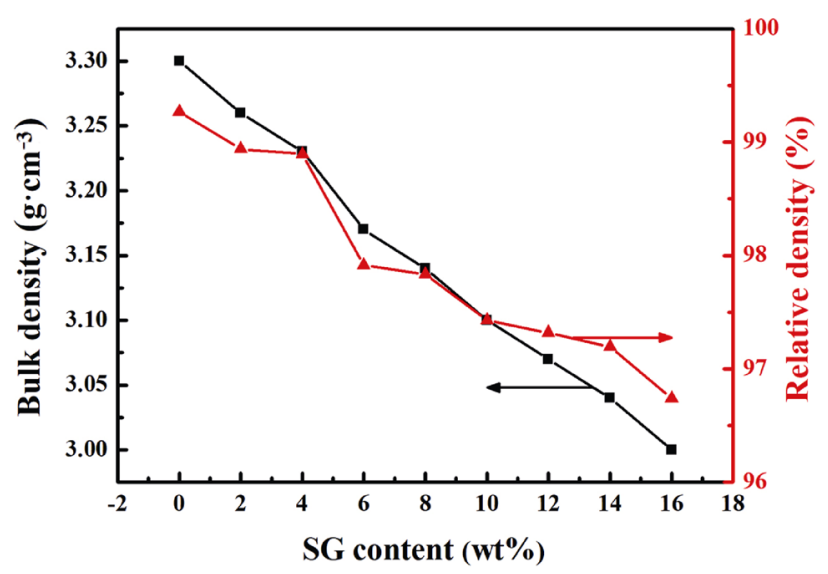

Fig. 5 Bulk density and relative density of SG/AlN composites with different SG contents. inhibits the sintering process of the SG/AlN composites. To explain the decrease in density of the composite as the amount of SG increases, the micromorphology, location, and distribution of SG particles within the materials, the microstructure and chemical composition of the SG/AlN composites were further characterized through SEM, EDS, and element mapping [48,51,52].

The SEM, EDS, and element mapping diagrams of the composite with $4 \mathrm{wt} \% \mathrm{SG}$ are provided in Fig. 6. The red area in Fig. 6(b) indicates the SG particles, as confirmed by the combined analysis of element mapping and EDS. The SG particles, with a significantly different morphology from the AlN matrix, can be well distinguished in Figs. 6(a) and 6(c). To more clearly observe the location and distribution of SG inside the AlN matrix, the fracture surfaces of the sintered samples with $0-12 \mathrm{wt} \% \mathrm{SG}$, were ultrasonically cleaned and then characterized using SEM and EDS analyses. As is shown in Fig. 7, the SG shows a clear fault-like structure after ultrasonication. Meanwhile, the fine AlN particles and SG particles on the fracture surface of the ultrasonicated sample were cleared away, showing a clearer fracture morphology in comparison with the non-ultrasonicated sample. Figure 8 shows the fracture 

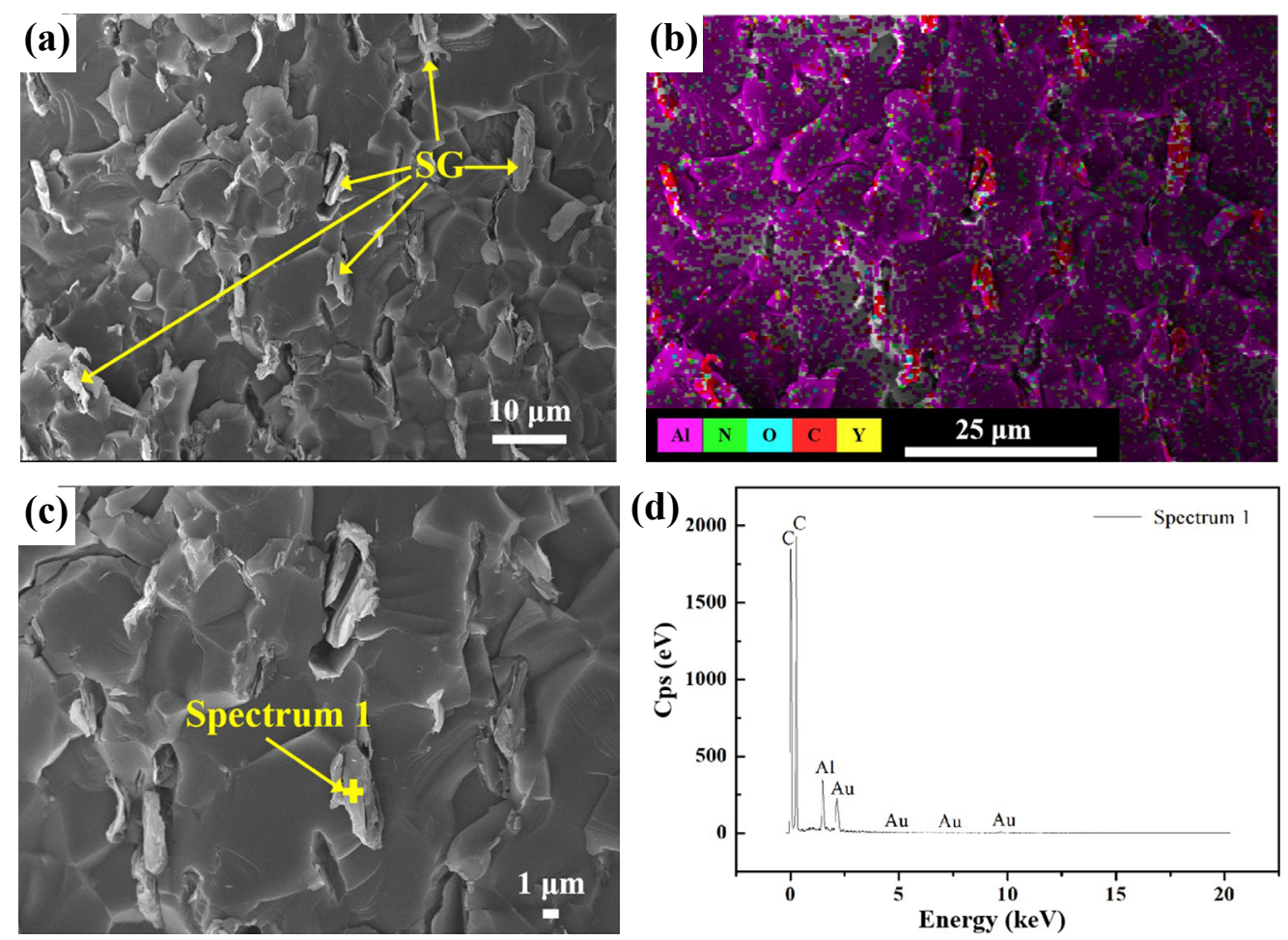

Fig. 6 (a) Microstructure, (b) EDS mapping, (c) high-resolution microstructure, and (d) EDS diagrams of 4 wt\% SG/AlN composite without ultrasonic cleaning.
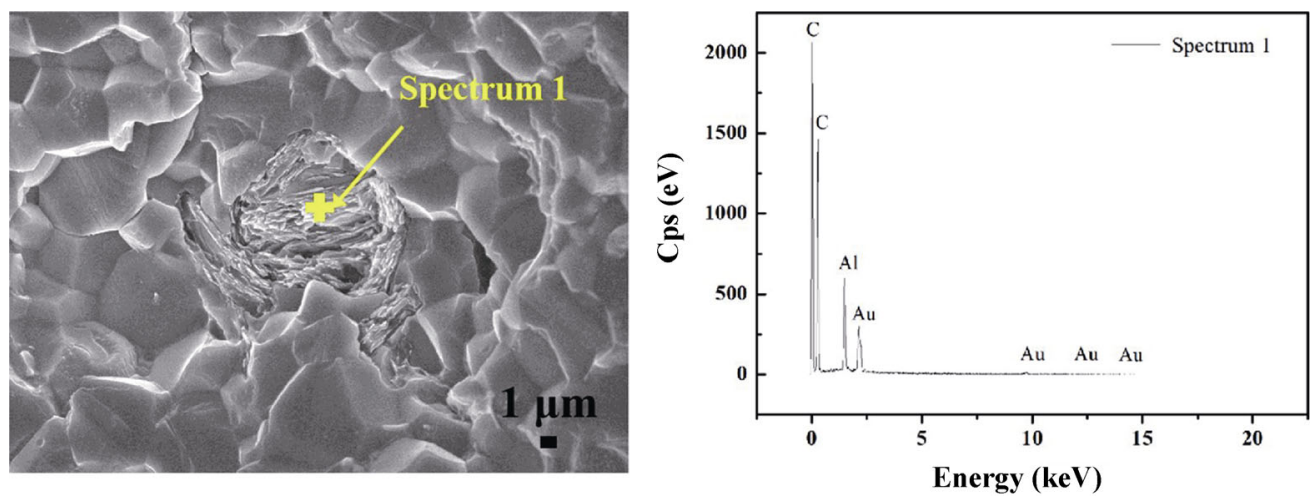

Fig. 7 Microstructure (ultrasonic cleaning) and EDS diagrams of $4 \mathrm{wt} \% \mathrm{SG} / \mathrm{AlN}$ composite.

morphologies of the composites containing different SG contents. Overall, the SG particles and AIN grains, although tightly bonded, showed significantly different morphologies, which can be clearly distinguished in all the composites. The SG particles were distributed homogeneously in the AlN matrix. Compared with that of the pristine SG shown in Fig. 1, the micromorphology of the SG inside the sintered sample suffered some damage and exhibited a pronounced deformation, which can be attributed to the uniaxial pressure applied during the sintering process. Nevertheless, most of the SG particles inside the composites maintain their 3D morphology after sintering, which is an obvious distinction from the 2D morphology of flake graphite $[25,27,33]$. Besides, none of these composites exhibited a pronounced behavior based on orientation, whether parallel or perpendicular to the pressure directions inside the sintered body. This is obviously differed from the orientated flake graphite in the AlN/graphite composite reported by Zhang et al. [25], suggesting that orientation alignment and anisotropy can be alleviated to some extent by using spherical graphite. Whereas, a significant agglomeration of SG particles can be observed in the composites with 10 and $12 \mathrm{wt} \%$ SG, implying that at high SG contents, the SG particles experience an increased difficulty in dispersion. 

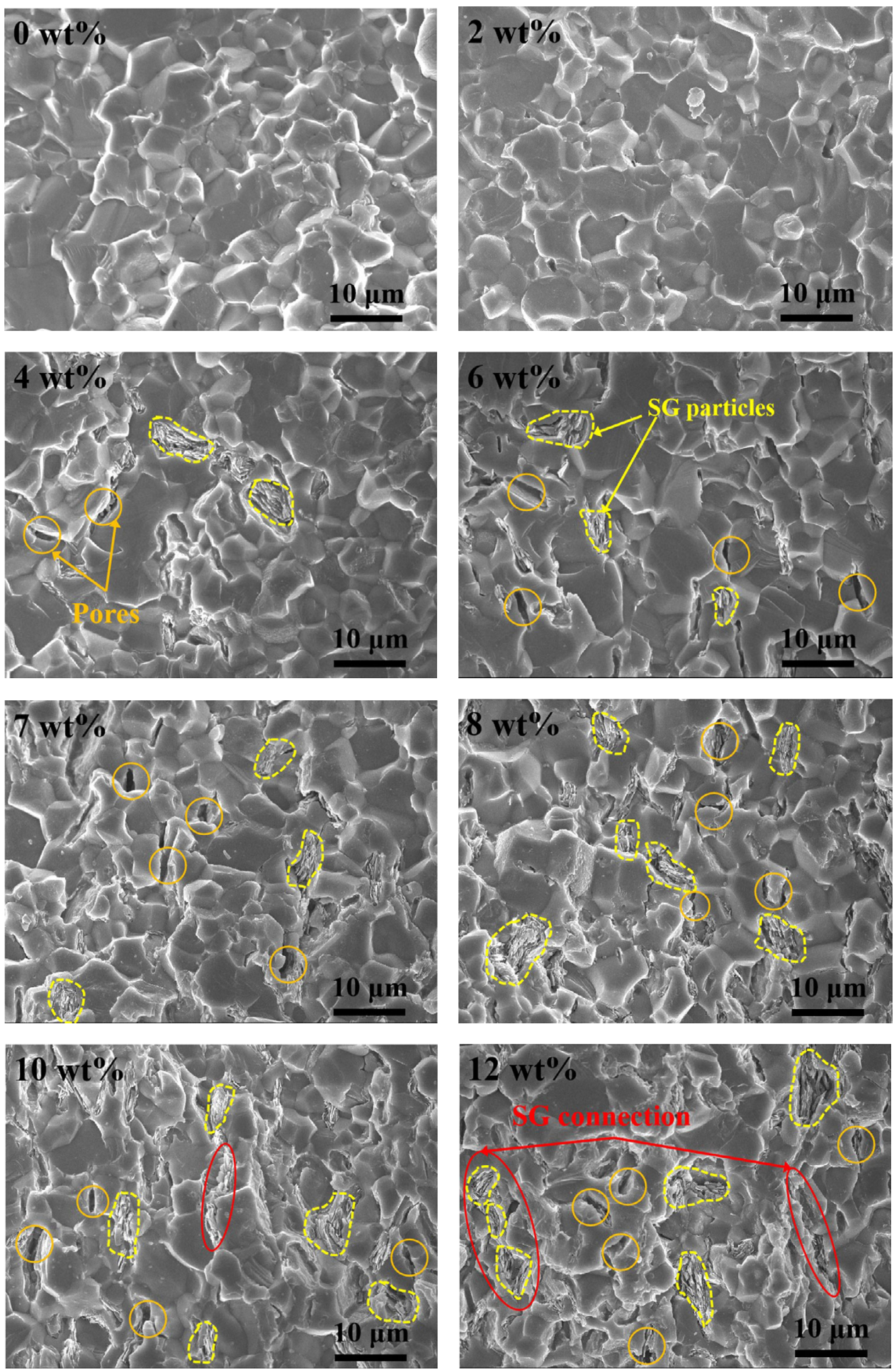

Fig. 8 Fracture morphologies of SG/AIN composites with different SG contents.

As shown in Fig. 8, the average AlN grain size of a monolithic AlN ceramic is $\sim 7 \mu \mathrm{m}$, and that of the composite with $12 \mathrm{wt} \% \mathrm{SG}$ is $5 \mu \mathrm{m}$. Compared to the decrease in the AlN grain size from 6.5 to $3.5 \mu \mathrm{m}$, as the graphene content increased from 0 to $7.28 \mathrm{vol} \%$ (5 wt\%), in graphene/AlN composites prepared via hot-pressing sintering [8], the introduction of SG into the AIN matrix only slightly inhibited the growth of AlN grains, which may be ascribed to the lower SG/AlN grain boundary interface in SG/AlN composites relative to that of the AlN-based composites containing 2D flake materials. The fewer SG/AIN interfaces sufficiently 
decrease the adverse impact of the incorporation of SG on the AlN mass transfer, thereby alleviating the inhibition of AlN grain growth. As the amount of SG incorporation increases, the SG/AlN heterogeneous interface grows and has a non-negligible effect on the mass transfer process of $\mathrm{AlN}$ and the migration process in the AlN grain boundary. These hinder the sintering process of the materials, increasing the number of pores within the material and accordingly decreasing the densification.

\section{3 Mechanical properties}

To evaluate the mechanical properties of the SG/AlN composite ceramics, the flexural strength and fracture toughness of the SG/AlN composite as a function of SG content are obtained and shown in Fig. 9. The strength of the composites decreases monotonically from 358 to $240 \mathrm{MPa}$ as the amount of SG increases from 0 to $12 \mathrm{wt} \%$, indicating that the addition of $\mathrm{SG}$ causes damage to the flexural strength of the composite. According to the fracture morphology analysis, the decrease in the strength is mainly caused by the increasing number of pores in the composite and the weakening of the interfacial bonding between the SG particles and AlN matrix as more SG is incorporated into the composite, which greatly reduces the energy required for crack propagation during the fracture process.

The fracture toughness of the composites exhibits an increasing trend at first and then decreases as the SG increases, reaching the maximum of $3.8 \mathrm{MPa} \cdot \mathrm{m}^{1 / 2}$ at $4 \mathrm{wt} \% \mathrm{SG}$, which is $27 \%$ more than that of the monolithic AlN ceramic, revealing that a moderate addition of SG has a certain toughening effect on the SG/AlN composites. Fracture toughness is the ability of a material to resist crack propagation, and the main

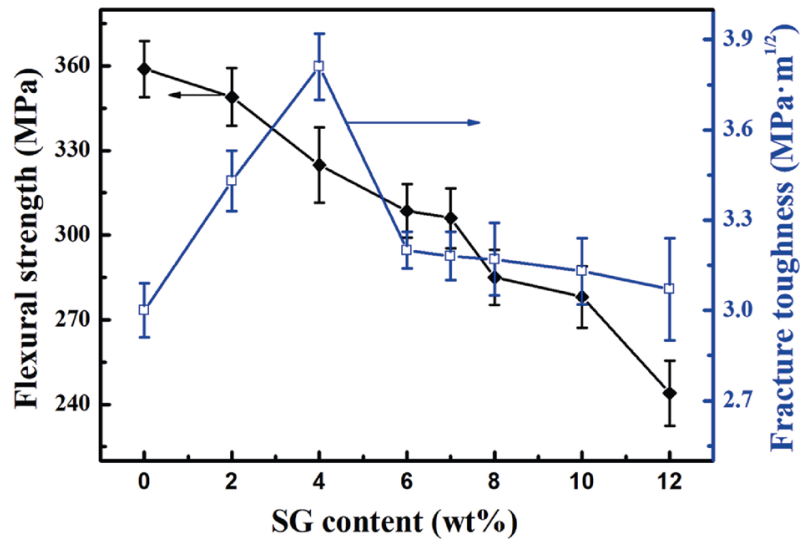

Fig. 9 Mechanical properties of SG/AlN composites with different SG contents.

toughened mechanism that occurs in the SG/AlN composites can be determined through the SEM images of the fracture morphology. As shown in Fig. 8, SG particles are dispersed homogeneously inside the composites, and composites with low SG contents exhibit a high densification, which endows a strong interfacial bonding force between the SG particles and the AlN matrix. The high-resolution fracture morphologies of the sample with $4 \mathrm{wt} \% \mathrm{SG}$ after ultrasonic cleaning and without ultrasonic cleaning are presented in Figs. 10(a) and 10(b), respectively. As shown in Fig. 10(a), the SG particles are tightly pinned inside the AlN grains, which induce a pinning effect in the material and consequently promote crack deflection during the crack propagation stage. In addition, Fig. 10(b) reveals that there are numerous extracted SG particles on the fracture surface, which is mainly because the SG particles were slightly deformed during the sintering process and became non-equiaxed particles. Considering the behavior of composite ceramics toughened by non-equiaxed materials such as graphene, carbon fibers, and CNTs [8], the extracted SG implies
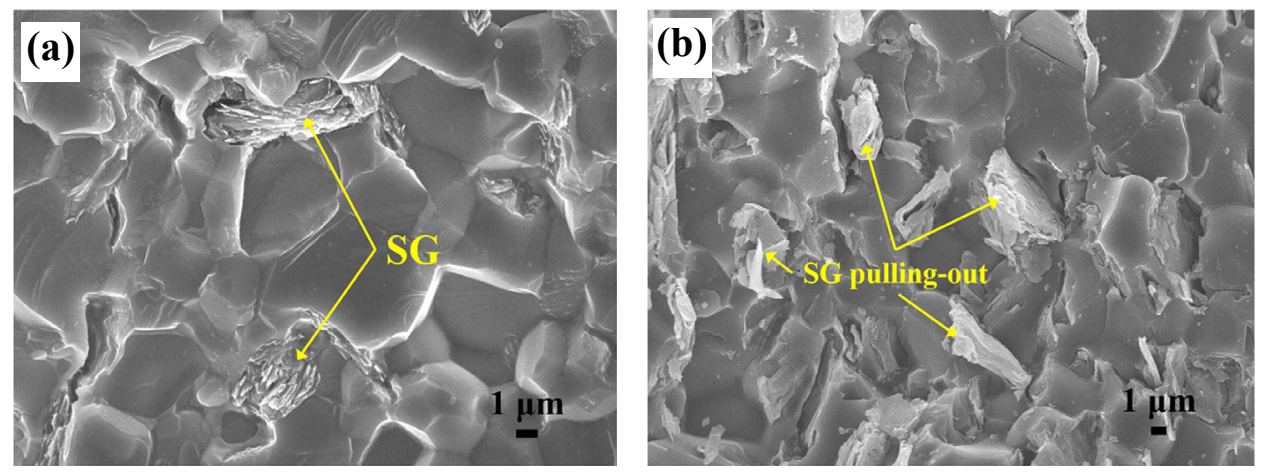

Fig. 10 High-resolution fracture morphologies of $4 \mathrm{wt} \%$ SG/AlN composite: (a) with ultrasonic cleaning and (b) without ultrasonic cleaning. 
that numerous SG bridging and pulling-out have been generated during the fracture process, thus consuming a large quantity of fracture energy. This phenomenon reasonably toughens the SG/AIN composites. However, at higher SG contents, the increasing pores and the consequent decrease in density weaken the interfacial bonding between the AIN grains and SG particles, which has a significant and detrimental effect on the mechanical properties of the composite. As a result, a decreased fracture toughness is observed when the SG content exceeds $4 \mathrm{wt} \%$.

\section{4 Thermal properties}

To investigate the thermal properties of the SG/AlNbased composites, the thermal diffusivity $\alpha$ and thermal conductivity $\lambda$ of the SG/AIN composite ceramics with varying SG contents were measured and are presented in Fig. 11. Generally, both $\alpha$ and $\lambda$ values of the composite ceramics exhibit a remarkable downtrend as the SG content increases from 0 to $16 \mathrm{wt} \%$. The $\alpha$ and $\lambda$ of monolithic AlN ceramic are $46.93 \mathrm{~mm}^{2} \cdot \mathrm{s}^{-1}$ and $115 \mathrm{~W} \cdot \mathrm{m}^{-1} \cdot \mathrm{K}^{-1}$, respectively. The $\alpha$ of the composite with an SG content of $6,7,8$, and $10 \mathrm{wt} \%$ is 37.41 , $35.9,34.30$, and $33.22 \mathrm{~mm}^{2} \cdot \mathrm{s}^{-1}$, respectively, and the $\lambda$ of the composite with an SG content of $6,7,8$, and $10 \mathrm{wt} \%$ is $88.65,84.5,80.44$, and $76.82 \mathrm{~W} \cdot \mathrm{m}^{-1} \cdot \mathrm{K}^{-1}$, respectively. These reveal that the addition of $\mathrm{SG}$ is detrimental to the thermal properties of the SG/AIN composites. Surprisingly, the $\alpha$ and $\lambda$ of the composite with $12 \mathrm{wt} \% \mathrm{SG}$ exhibit an increase to $34.76 \mathrm{~mm}^{2} \cdot \mathrm{s}^{-1}$ and $79.53 \mathrm{~W} \cdot \mathrm{m}^{-1} \cdot \mathrm{K}^{-1}$, respectively, instead of decrements. Further addition of $\mathrm{SG}$ to $16 \mathrm{wt} \%$ leads to the minimum $\alpha$ and $\lambda$ values of $26.54 \mathrm{~mm}^{2} \cdot \mathrm{s}^{-1}$ and $64.04 \mathrm{~W} \cdot \mathrm{m}^{-1} \cdot \mathrm{K}^{-1}$, respectively.

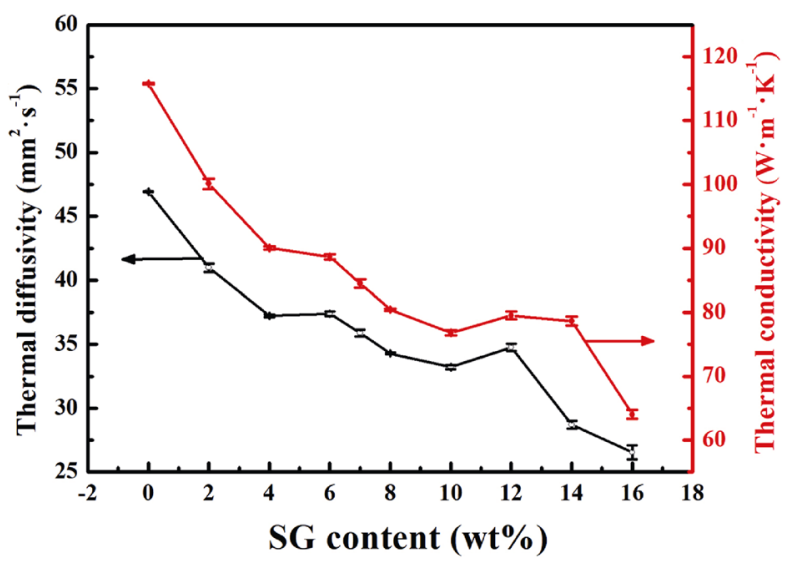

Fig. 11 Thermal diffusivity $\alpha$ and thermal conductivity $\lambda$ of SG/AIN composites with different SG contents.
As a covalently bonded inorganic compound, the $\lambda$ of AlN crystals is strongly associated with phonon heat conduction [53], as described by the following equation [54]:

$$
\lambda=\frac{1}{3} c v l
$$

where $c$ is the specific heat capacity, $v$ is the mean velocity of the phonon, and $l$ refers to the mean free path of the phonon. Enhanced phonon scattering results in the decrease of $l$, thereby reducing $\lambda$ [53]. The phonon scattering in AlN-based composites mainly originates from various defect-phonon scattering, such as vacancies, dislocations, grain boundary interfaces, and pores [7]. For the SG/AlN composites, the growing SG/AIN interface as the SG addition enhances the phonon scattering and generates more interfacial thermal resistance, thus inducing a negative effect on the $\lambda$ of the composites [8,54,55]. In addition, as the sources of scattering, the increasing number of pores at higher SG contents also contributes to the decrease in $\lambda$. The effect of porosity on $\lambda$ of a material can be expressed as follows [56]:

$$
\lambda=\lambda_{0}\left(1-\frac{3}{2} \phi\right)
$$

where $\lambda_{0}$ represents the thermal conductivity of a dense material and $\phi$ is the porosity.

Equation (3) shows that $\lambda$ has an inverse relationship with the $\phi$ of a material, and hence, the increasing pores as the SG addition also contribute a lot to the degradation of the $\lambda$ of the SG/AlN composites. The abnormal increase in $\lambda$ at $12 \mathrm{wt} \%$ SG may be ascribed to the formation of partial thermal-conduction paths caused by the connection of SG particles at higher SG contents. However, the further addition of SG seriously decreases the densification and increases the number of pores in the composites, thus resulting in a dramatically decrease in the $\lambda$ value to $64.04 \mathrm{~W} \cdot \mathrm{m}^{-1} \cdot \mathrm{K}^{-1}$ at $16 \mathrm{wt} \%$ SG.

In comparison with other AlN-based attenuating ceramics, the thermal properties of AlN-based composites containing different attenuating agents are tabulated in Table 1 . Generally, the $\lambda$ values of the SG/AIN composites are significantly higher than that of $\mathrm{AlN} / \mathrm{SiC}$ attenuating composite ceramics $\left(40\right.$ to $70 \mathrm{~W} \cdot \mathrm{m}^{-1} \cdot \mathrm{K}^{-1}$ $[1,10,11])$ at the same content of the second phase. Simultaneously, in comparison to the AlN-based composites containing 1D/2D carbon materials, such as graphene and carbon nanotubes, as the second phase 
Table 1 Thermal properties of AIN-based composites with different second phases

\begin{tabular}{|c|c|c|c|c|c|c|c|}
\hline Sample & Sintering method & $\begin{array}{l}\text { Purity of raw } \\
\text { AlN powders }\end{array}$ & $\begin{array}{l}\text { AlN grain } \\
\text { size }(\mu \mathrm{m})\end{array}$ & $\begin{array}{l}\text { Second phase } \\
\text { content }\end{array}$ & $\begin{array}{l}\text { Thermal diffusivity } \\
\qquad\left(\mathrm{mm}^{2} \cdot \mathrm{s}^{-1}\right)\end{array}$ & $\begin{array}{l}\text { Thermal conductivity } \\
\left(\mathrm{W} \cdot \mathrm{m}^{-1} \cdot \mathrm{K}^{-1}\right)\end{array}$ & Ref. \\
\hline $\begin{array}{c}\text { Graphene } \\
\text { nanosheet/AlN }\end{array}$ & Hot-pressing & $97.70 \%$ & $\leqslant 3.5$ & $10 \mathrm{vol} \%$ & & 35.9 (through-plane) & {$[8]$} \\
\hline SWCNT/AlN & Hot-pressing & $97.99 \%$ & 2 & $6 \mathrm{vol} \%$ & & 62 & [9] \\
\hline $\mathrm{SiC} / \mathrm{AlN}$ & $\begin{array}{l}\text { Plasma activated } \\
\text { sintering }\end{array}$ & $99.99 \%$ & 3 & $10 \mathrm{wt} \%$ & 15 & 36 & {$[11]$} \\
\hline $\begin{array}{c}\text { Graphene } \\
\text { platelets/AlN }\end{array}$ & $\begin{array}{l}\text { Spark plasma } \\
\text { sintering }\end{array}$ & $99.90 \%$ & $1.73 \pm 0.02$ & $9.5 \mathrm{wt} \%$ & 4.64 & 19.8 & [23] \\
\hline $\mathrm{SiC} / \mathrm{AlN}$ & Hot-pressing & $98.50 \%$ & - & $10 \mathrm{wt} \%$ & & 65 & {$[57]$} \\
\hline Graphene/AlN & Hot-pressing & $97.99 \%$ & 6 & $10 \mathrm{wt} \%$ & 18.95 & 39.7 (through-plane) & {$[58]$} \\
\hline $\begin{array}{c}\text { Graphene } \\
\text { platelets/AlN }\end{array}$ & $\begin{array}{l}\text { Spark plasma } \\
\text { sintering }\end{array}$ & $\leqslant 99.22 \%$ & $2 \pm 1.4$ & $8 \mathrm{wt} \%$ & $\begin{array}{l}19 \\
37\end{array}$ & $\begin{array}{c}43 \text { (through-plane) } \\
84 \text { (in-plane) }\end{array}$ & {$[59]$} \\
\hline $\begin{array}{c}\text { Spherical } \\
\text { graphite/AlN }\end{array}$ & Hot-pressing & $99.90 \%$ & $\sim 7$ & $10 \mathrm{wt} \%$ & 33.22 & 76.8 (through-plane) & This work \\
\hline
\end{tabular}

[7-9], at the same content, the SG/AIN composite shows a relatively higher $\lambda$ as well. For example, the $\lambda$ of the AlN/graphene composite containing $0.1 \mathrm{vol} \%(0.07 \mathrm{wt} \%)$ graphene prepared by Simsek et al. [7] is only $74 \mathrm{~W} \cdot \mathrm{m}^{-1} \cdot \mathrm{K}^{-1}$ in the direction parallel to the graphene plane, and that of the $10 \mathrm{vol} \%(7 \mathrm{wt} \%)$ graphene nanosheet/AlN composite reported by Yun et al. [8] is as low as $40 \mathrm{~W} \cdot \mathrm{m}^{-1} \cdot \mathrm{K}^{-1}$. Similarly, carbon nanotubes have been reported to have a thermal conductivity up to $6600 \mathrm{~W} \cdot \mathrm{m}^{-1} \cdot \mathrm{K}^{-1}$, whereas the AlN/CNT composite with $6 \mathrm{vol} \%(4 \mathrm{wt} \%)$ CNTs shows a relatively low $\lambda$ of $62 \mathrm{~W} \cdot \mathrm{m}^{-1} \cdot \mathrm{K}^{-1}$ [9]. All of these values are lower than the $\lambda$ value of SG/AlN composite with $10 \mathrm{wt} \% \mathrm{SG}$ prepared in this study at $76.82 \mathrm{~W} \cdot \mathrm{m}^{-1} \cdot \mathrm{K}^{-1}$, indicating that SG had the least impact on the $\lambda$ of AlN-based composites relative to other types of attenuating agents, which is credited to its spherical morphology. Similarly, Ren et al. [60] found that the thermal conductivity of spherical BN/PDMS composites $\left(2.30 \mathrm{~W} \cdot \mathrm{m}^{-1} \cdot \mathrm{K}^{-1}\right)$ is almost four times higher than that of platelet-like $\mathrm{BN} / \mathrm{PDMS}$ composites $\left(0.60 \mathrm{~W} \cdot \mathrm{m}^{-1} \cdot \mathrm{K}^{-1}\right)$. It is mainly because the spherical filler can not only reduce the interface thermal resistance and phonon scattering compared with platelet-like one, but also decrease the BN agglomeration and thus greatly promotes heat conduction.

As schematically shown in Figs. 12(a) and 12(b), compared to the flake-shaped heterogeneous interface of AlN-based composites containing 2D flake graphite, ideally, the SG/AlN interface surrounding the SG should also have a spherical morphology, which endows a remarkably lower cross-sectional area for the heterogeneous interface in the direction of thermal conduction. Additionally, in comparison with graphene,
CNTs and other $1 \mathrm{D} / 2 \mathrm{D}$ attenuating agents incorporated at the same volume fraction, and the addition of SG shows a slightly inhibited effect of the AIN grains. Zhang et al. [25] reported that the larger the particle size is, the lower the thermal conductive barrier it provides. It can be inferred that the relatively larger AlN grains due to the addition of SG extremely lessen the conductive barrier, and this is in greatly contrast with the sharp increase in the interfacial barrier of graphene/ AlN composites as the AlN particle size decreases $[8,23,59]$. All the above factors can considerably diminish the interfacial thermal resistance of the SG/AIN composites. The effect of interfacial thermal resistance on heat conduction can be given by Eq. (4) [61]:

$$
Q_{i}=\Delta T / R_{i}
$$

where $Q_{i}$ represents the value of the heat flux at interface, $\Delta T$ is the temperature difference at interface, and $R_{i}$ is the interfacial thermal resistance. It can be deduced that the lower interfacial thermal resistance delivers a higher heat flux through the interface. Consequently, the SG/AIN composites with a lower interfacial thermal resistance exhibit a significant improved heat-conduction ability.

On the other side, since SG has a low-anisotropic $\lambda$, as distinguished from that of $2 \mathrm{D}$ materials with a uniaxially high $\lambda$, regardless of directions, there should be two thermally conductive paths within the SG/AIN composites. As indicated by the yellow arrow in Fig. 12(a), one is the SG-AlN thermally conductive path, and the other is the AlN matrix thermally conductive path, both of which hugely promote the $\lambda$ of the SG/AIN composites. The synergistic effect of the reduced interfacial thermal resistance and the 
(a)

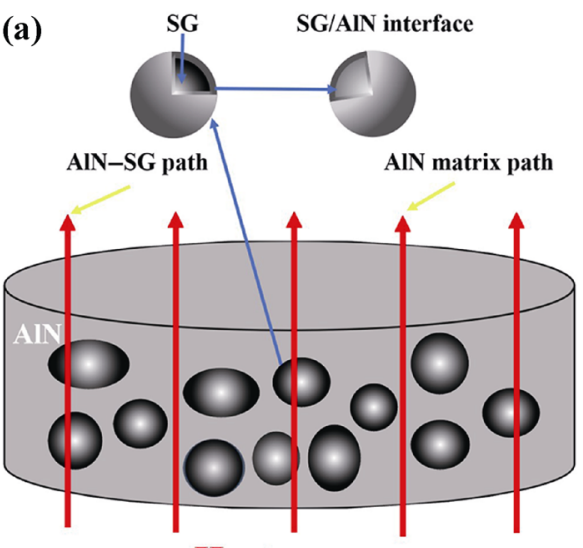

Heat energy

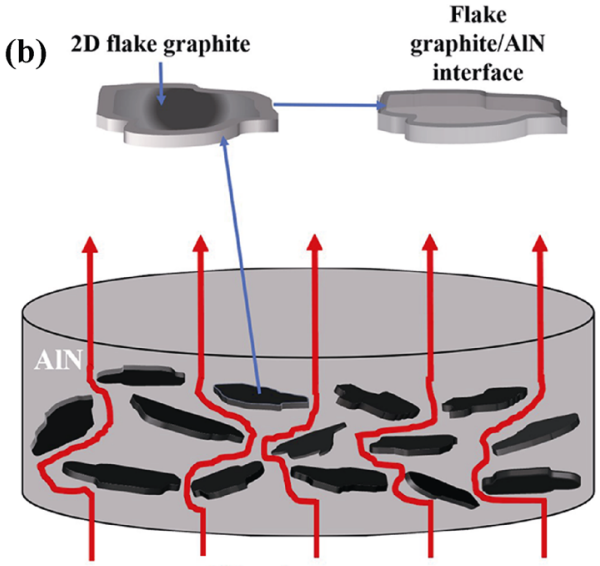

Heat energy

Fig. 12 Schematic diagrams of thermally conductive paths in composite filled with different shaped second phases: (a) spherical graphite and (b) 2D flake graphite.

low anisotropic thermal conductivity of SG can deliver a higher $\lambda$ for the SG/AlN composites. Moreover, the issue of the anisotropic $\lambda$ for the composites containing 1D/2D carbonaceous materials can also be alleviated by the weak orientation alignment of SG, further evidencing the potential of applying SG in the preparation of highly thermally conductive microwave attenuating materials with low anisotropy.

\section{5 Dielectric properties}

The microwave absorption performance of a nonmagnetic absorption material is strongly dependent on its dielectric properties, such as the real dielectric constant $\varepsilon^{\prime}$, imaginary dielectric constant $\varepsilon^{\prime \prime}$, and dielectric loss. The real and imaginary parts of the dielectric constant refer to the polarization and lossy ability of the material under an applied electromagnetic field, respectively, and the dielectric loss is reflected by the $\tan \delta$ value [62]. The dielectric constant and dielectric loss as a function of microwave frequency

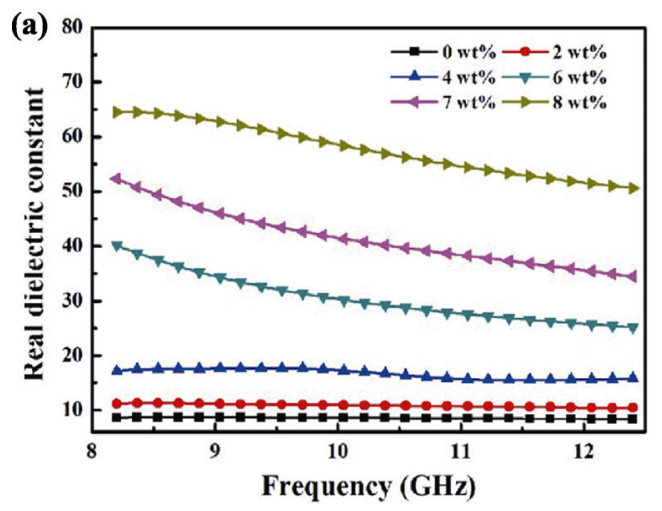

(8.2-12.4 GHz) of the SG/AlN composites with different SG contents are depicted in Figs. 13 and 14, respectively. Both the dielectric constant and dielectric loss of the composites show a significant increment as the SG content increases from 0 to $8 \mathrm{wt} \%$. The $\varepsilon^{\prime}, \varepsilon^{\prime \prime}$, and $\tan \delta$ values of the monolithic AlN ceramic are 8.3-8.7, 0.03-0.07, and 0.004-0.008, respectively, showing an extremely low dielectric loss. Whereas the $\varepsilon^{\prime}, \varepsilon^{\prime \prime}$, and $\tan \delta$ values for the $8 \mathrm{wt} \%$ composite are 50-64, 30-32, and 0.46-0.59, respectively, implying that the addition of SG has a pronounced improved effect on the dielectric loss of the SG/AIN composite materials.

The $\varepsilon^{\prime}$, which reflects the polarization ability of the material, is closely linked with the ability of the material to store charges [63], and it is given by Eq. (5) [62]:

$$
\varepsilon^{\prime}=\frac{\varepsilon_{\mathrm{s}}-\varepsilon_{\infty}}{1+\omega^{2} \tau^{2}}+\varepsilon_{\infty}
$$

where $\varepsilon_{\mathrm{s}}$ is the static dielectric constant, $\varepsilon_{\infty}$ is the optical dielectric constant, $\tau$ is the polarization relaxation

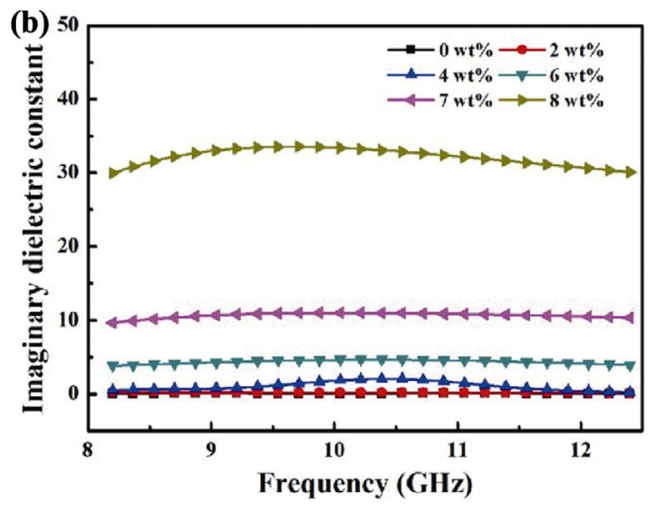

Fig. 13 Dielectric constants of SG/AlN composites with different SG contents. 


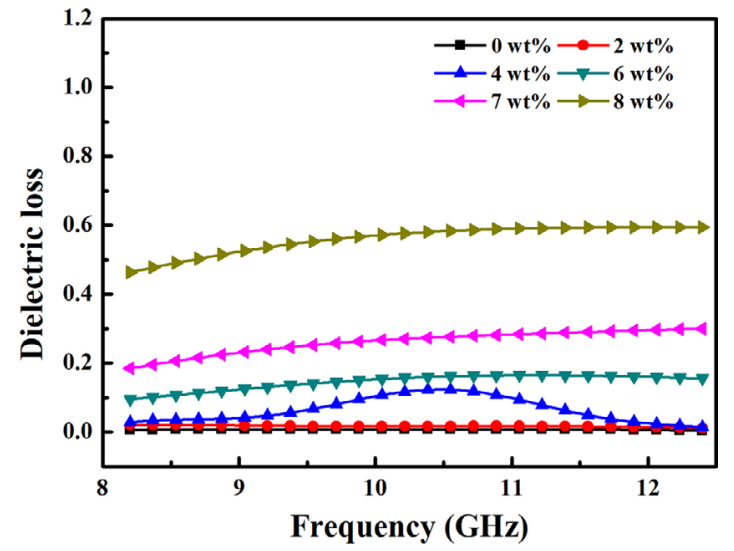

Fig. 14 Dielectric loss of SG/AlN composites with different SG contents.

time, and $\omega$ is the angular frequency. The conductive SG particles inside the insulating AlN matrix, act as electrode plates and readily create a mini-capacitor effect. The shorter the distance between conductive SG particles, the further improved the capacitance of the composites, that is, the enhanced mini-capacitor effect. From this, the ability of the composites to store charges is sufficiently improved and in turn enhances the $\varepsilon^{\prime}$ value. The $\varepsilon^{\prime \prime}$ value can be calculated using the following Eq. (6) $[63,64]$ :

$$
\varepsilon^{\prime \prime}=\frac{\sigma}{\omega \varepsilon_{0}}+\frac{\varepsilon_{\mathrm{s}}-\varepsilon_{\infty}}{1+\omega^{2} \tau^{2}} \omega \tau=\varepsilon_{\mathrm{c}}+\varepsilon_{\text {relax }}
$$

where $\sigma$ is the electrical conductivity of the material, $\varepsilon_{0}$ is the dielectric constant of free space $\left(8.854 \times 10^{-12}\right.$
$\mathrm{F} \cdot \mathrm{m}^{-1}$ ) [62], and $\varepsilon_{\mathrm{c}}$ and $\varepsilon_{\text {relax }}$ are the conduction loss and Debye relaxation loss, respectively. The imaginary part of the dielectric constant is proportional to the conductivity of the material, that is, conduction loss. As the conductive phase SG is incorporated into the matrix, it gradually forms a 3D conductive network, which then significantly increases the electrical conductivity of the composite material and the electronic migration on the surface of the SG particles increases significantly, thereby enhancing the conduction loss of the material. It can be deduced from Eqs. (5) and (6) that the $\varepsilon^{\prime}$ and $\varepsilon^{\prime \prime}$ values of the materials are closely related to the Debye relaxation loss. Based on the Debye theory, if there is no consideration of the influence of conduction loss on the $\varepsilon^{\prime \prime}$ value, the Debye relaxation loss can be deduced from the $\varepsilon^{\prime \prime}-\varepsilon^{\prime}$ curves, and the relationship between the real and imaginary parts of the dielectric constant can be described as following [65]:

$$
\left(\varepsilon^{\prime \prime}\right)^{2}+\left(\varepsilon^{\prime}-\frac{\varepsilon_{\mathrm{s}}+\varepsilon_{\infty}}{2}\right)^{2}=\left(\frac{\varepsilon_{\mathrm{s}}-\varepsilon_{\infty}}{2}\right)^{2}
$$

If there is a polarization relaxation behavior existing in the material, a semicircle occurs in the $\varepsilon^{\prime \prime}-\varepsilon^{\prime}$ curve, which is called the Cole-Cole semicircle [65]. The $\varepsilon^{\prime \prime}-\varepsilon^{\prime}$ curves of the SG/AlN composites with varying SG contents are displayed in Fig. 15. No obvious semicircle is observed in the curves of the 0 and $2 \mathrm{wt} \%$ SG samples, whereas the samples containing $4,6,7$,
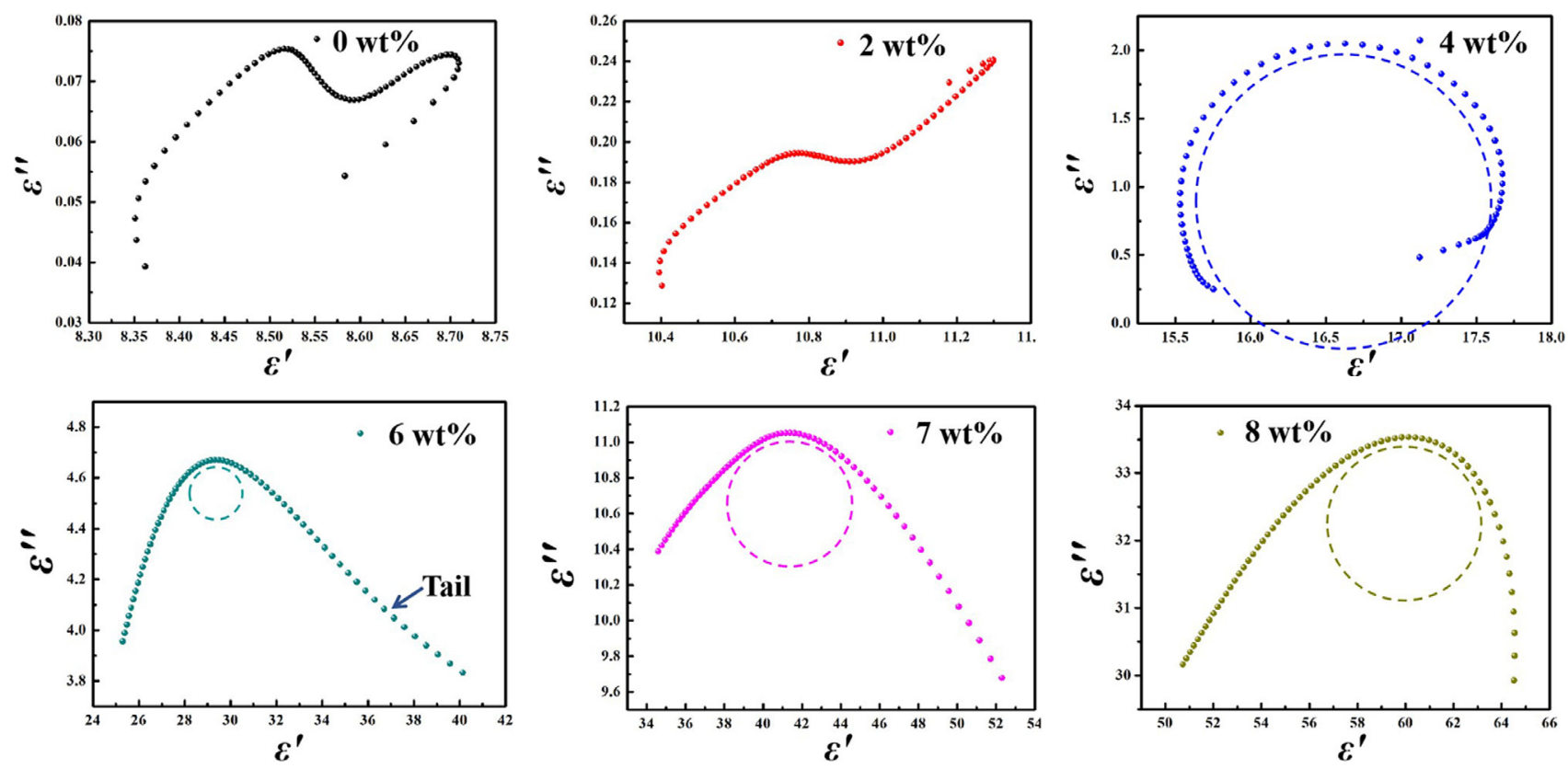

Fig. $15 \varepsilon^{\prime \prime}-\varepsilon^{\prime}$ curves of SG/AlN composites with different SG contents. 
and $8 \mathrm{wt} \%$ SG exhibit identifiable Cole-Cole semicircles. This indicates that the SG leads to an obvious polarization relaxation behavior in the composite, which should be attributed to the synergistic effect of $\mathrm{SG}$ particle, AlN grains, and SG/AIN heterogeneous interfaces.

In the SG/AIN composites, the electronic transport in the SG-SG microcapacitors is mainly realized via insulated AIN matrix, and the insulated AlN is equivalent to a tunneling resistance. The evenly dispersing $\mathrm{SG}$ in the AlN matrix means that the SG-SG microcapacitors and AlN grain resistance will form repeated polarizations inside the material. In addition, owing to the large mismatch between the electrical conductivities of AIN and $\mathrm{SG}$, the space charge polarization was strongly built as a result of the charge accumulation at the $\mathrm{SG} / \mathrm{AlN}$ heterogeneous interfaces, which can also be considered a microcapacitor. In this regard, the dielectric properties of SG/AlN composites can be expressed by the equivalent circuit. To have a better understanding of the effect of the addition of SG on the dielectric properties of the composites, the $\mathrm{AC}$ impedance of the 2-8 $\mathrm{wt} \%$ composites was tested and the relevant impedance spectra are shown in Figs. 16(a)-16(e). Combined with software analysis and repeated tests, the equivalent circuit that mostly fits the microregion in the composites is schematically shown in Fig. 16(f), wherein the red curves in Figs. 16(a)-16(e) are the fitting curves deserved from the equivalent circuit. The impedance $(Z)$ corresponding to the equivalent circuit can be given by Eq. (8):

$$
\frac{1}{Z}=\frac{1}{R+1 /\left(\mathrm{i} \omega C_{1}\right)}+\frac{1}{1 /\left(\mathrm{i} \omega C_{2}\right)}
$$

where $C_{1}$ represents $\mathrm{SG}-\mathrm{SG}$ microcapacitor, $C_{2}$ represents the microcapacitor corresponding to the space charge polarization, and $R$ represents the tunneling resistance of AlN grain. The $R, C_{1}$, and $C_{2}$ values of the equivalent circuit of the SG/AIN composites with different SG contents are presented in Table 2. Notably, the decreasing $R$ indicating that the conductivity of the composites was significantly improved by the SG addition. In contrast, the $C_{1}$ and $C_{2}$ exhibit a monotonous increase with the elevated SG contents, which suggests that more microcapacitor structures and space charge polarization are generated inside the material. These further demonstrates that the improved conductivity and the polarization relaxation composed of SG-SG microcapacitors, heterogeneous interfaces of AlN grain resistance and $\mathrm{SG} / \mathrm{AlN}$ resulting from the $\mathrm{SG}$ addition contribute a lot to the enhancement of the $\varepsilon^{\prime}$ and $\varepsilon^{\prime \prime}$ values. Whereas, aside from the typical Cole-Cole semicircle, a smooth tail is also observed in the $\varepsilon^{\prime \prime}-\varepsilon^{\prime}$ curves for the samples with 6-8 wt\% SG, which may be attributed to that the excessive conduction loss caused by the SG addition hides the effect of the relaxation process, the similar results can also be found in Refs. [65-67]. Accordingly, in parallel with the variation of the real and imaginary dielectric constants, the loss tangent $\tan \delta$ determined by $\varepsilon^{\prime}$ and $\varepsilon^{\prime \prime}$ also exhibits an improvement, suggesting that the addition of SG enhances the dielectric loss capability of the composite.

\section{6 Microwave absorption properties}

The microwave absorption property of material is usually characterized by the reflection loss $(R L)$, which is expressed according to Eq. (9) $[68,69]$ :

$$
R L=20 \lg \left|\frac{Z_{\text {in }}-Z_{0}}{Z_{\text {in }}+Z_{0}}\right|
$$

where $Z_{0}$ is the impedance in free space, and $Z_{\text {in }}$ is the incident impedance of the material surface, which can be obtained from Eq. (10) $[68,69]$ :

$$
Z_{\text {in }}=Z_{0} \sqrt{\frac{\mu_{r}}{\varepsilon_{r}}} \tanh \left(\mathrm{j} \frac{2 \pi f d}{c} \sqrt{\mu_{r} \varepsilon_{r}}\right)
$$

where $f$ refers to the frequency of the electromagnetic wave, $c$ is the speed of light $\left(3 \times 10^{8} \mathrm{~m} / \mathrm{s}\right), d$ denotes the material thickness, and $\varepsilon_{r}$ and $\mu_{r}$ are the complex permittivity and complex permeability of the material, respectively (for non-magnetic materials, $\mu_{r}$ is commonly set to 1) [70]. $R L$ is generally a negative value, and the smaller the value is, the stronger the absorption ability of the material. For instance, $R L$ values below -4 and $-10 \mathrm{~dB}$ mean that the material can absorb $36 \%$ and $90 \%$ of electromagnetic wave, respectively, and the latter case is considered as an effective absorption [68]. Figure 17 shows the $R L$ of the SG/AlN composites as a function of SG content at the thickness of $1 \mathrm{~mm}$. In the X-band, as the SG content increases from 0 to $8 \mathrm{wt} \%$, the $R L_{\min }$ of the composites gradually decreases first, and then increases. When the SG content is less than $6 \mathrm{wt} \%$, all the $R L_{\min }$ values are higher than $-4 \mathrm{~dB}$, indicating a poor absorption capability for electromagnetic waves. The $R L$ value of $7 \mathrm{wt} \%$ sample significantly decreases with the increasing frequency in the X-band, and it 
(a)

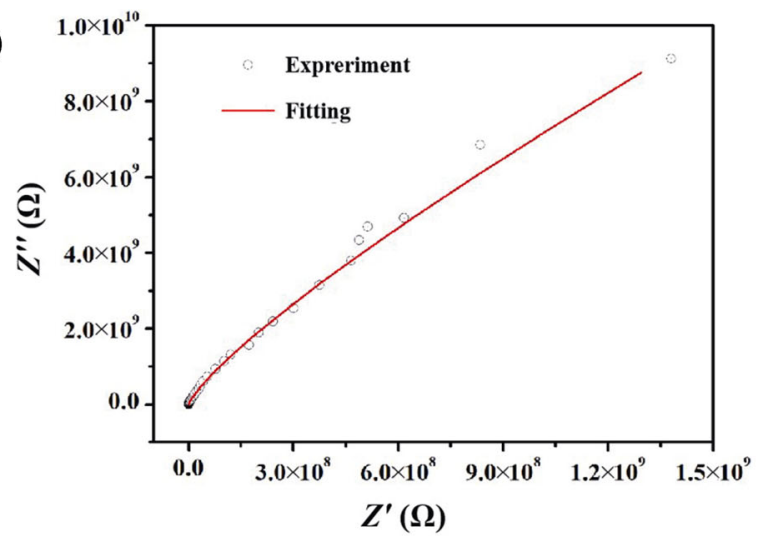

(c)

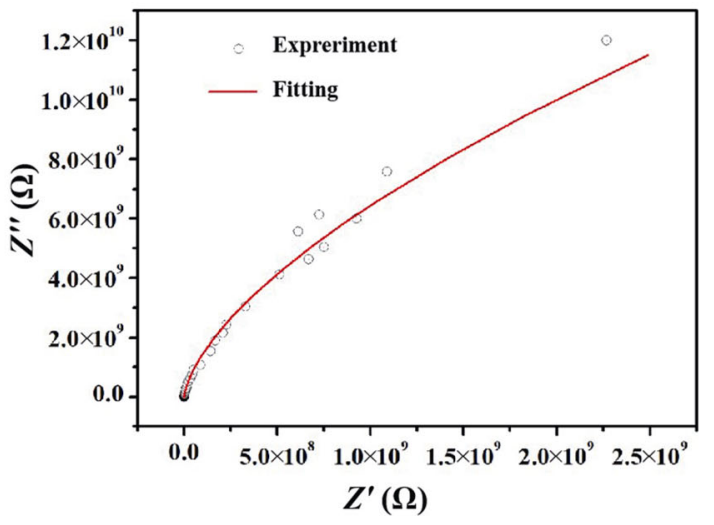

(e)

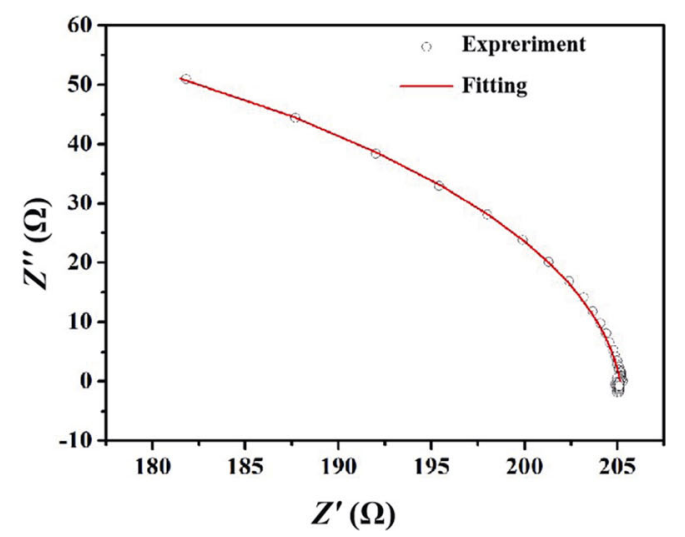

(b)

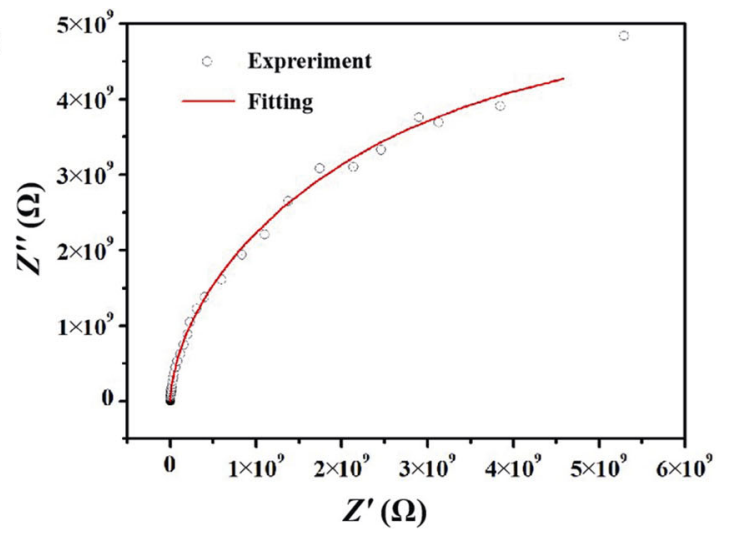

(d)

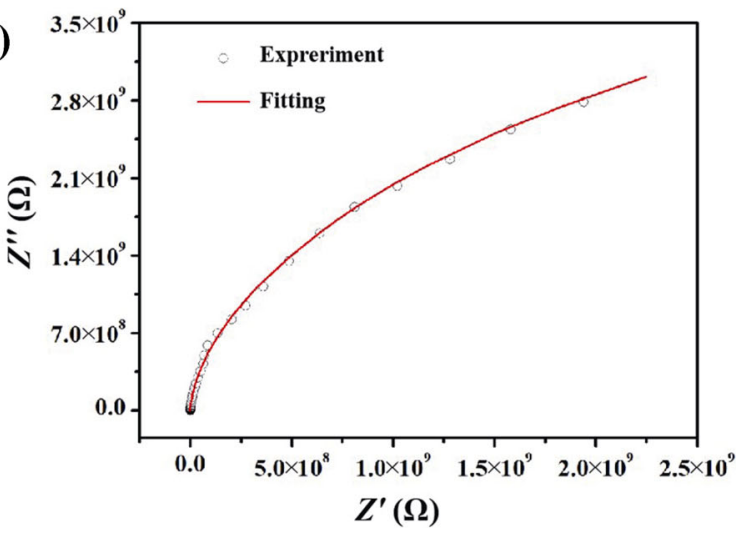

(f)

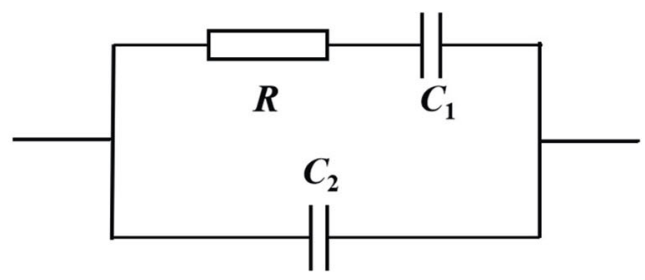

Fig. 16 Impedance spectra of the SG/AIN composites of (a) 2, (b) 4, (c) 6, (d) 7, (e) $8 \mathrm{wt} \%$, and (f) equivalent circuit model of a microregion in the composites.

Table 2 Modeled parameters of the equivalent circuit model in the SG/AIN composites

\begin{tabular}{cccc}
\hline SG content $(\mathrm{wt} \%)$ & $R$ & $C_{1}$ & $C_{2}$ \\
\hline 2 & $1.623 \times 10^{10}$ & $1.038 \times 10^{-11}$ & $3.641 \times 10^{-12}$ \\
4 & $6.433 \times 10^{9}$ & $4.681 \times 10^{-11}$ & $1.15 \times 10^{-11}$ \\
6 & $5.208 \times 10^{9}$ & $8.308 \times 10^{-11}$ & $1.291 \times 10^{-11}$ \\
7 & $4.578 \times 10^{9}$ & $1.077 \times 10^{-10}$ & $2.243 \times 10^{-11}$ \\
8 & 205.5 & $9.45 \times 10^{-9}$ & $8.423 \times 10^{-10}$ \\
\hline
\end{tabular}

shows the best absorption performance with a $R L_{\min }$ value of $-13.9 \mathrm{~dB}$ at $12.4 \mathrm{GHz}$. In comparison, the $\mathrm{SiC} / \mathrm{AlN}$ composites prepared by Li et al. [11] exhibited an optimized absorption ability with the $R L_{\min }$ of $-16.5 \mathrm{~dB}$ at $30 \mathrm{wt} \% \mathrm{SiC}$, whereas its thermal conductivity $\left(24.88 \mathrm{~W} \cdot \mathrm{m}^{-1} \cdot \mathrm{K}^{-1}\right)$ is significantly lower than that of $7 \mathrm{wt} \% \mathrm{SG} / \mathrm{AlN}$ composite $\left(84.5 \mathrm{~W} \cdot \mathrm{m}^{-1} \cdot \mathrm{K}^{-1}\right)$. This shows that a integrated strong attenuation and high thermal conductivity can be obtained by SG/AlN composites. 


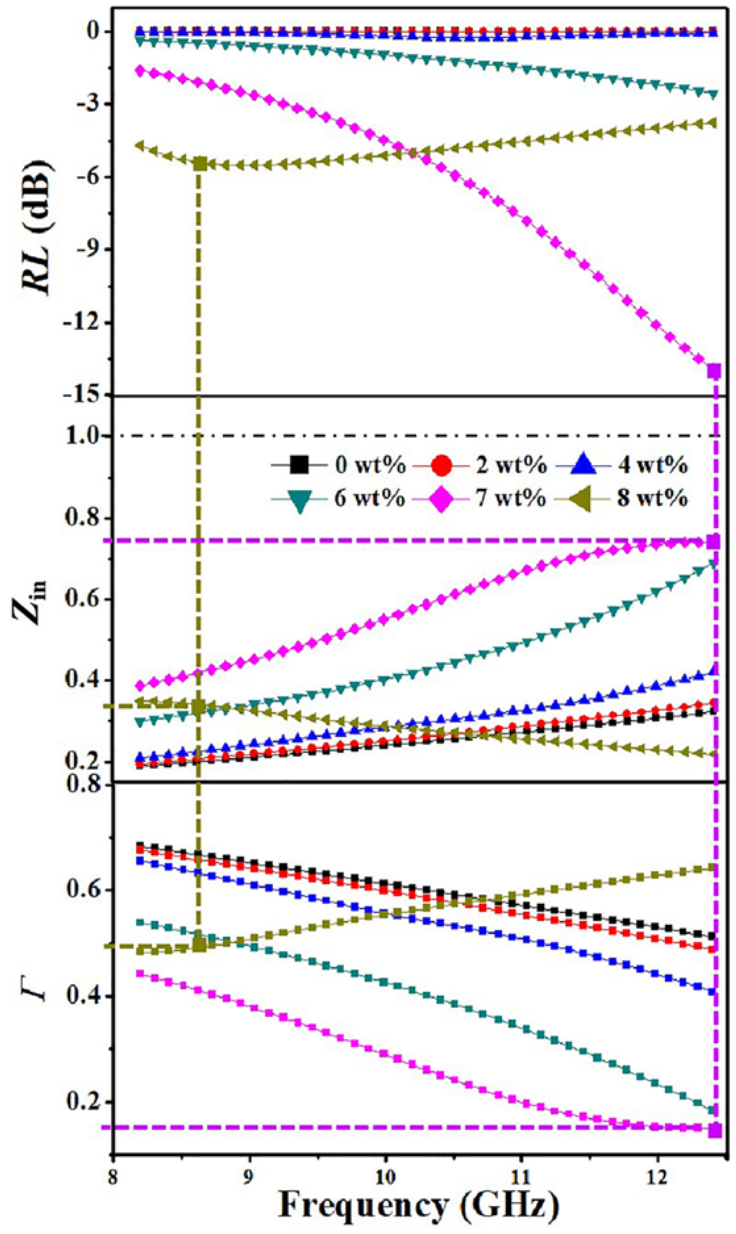

Fig. 17 Reflection loss, incident impedance, and reflection coefficient of SG/AIN composites with different SG contents.

The improved absorption ability of the sample should be attributed to the enhanced dielectric loss, which is mainly derived from the interfacial polarization loss and conduction loss as a result of the addition of SG. Additionally, the improved charge storage ability resulting from the enhanced mini-capacitor effect also boosts the microwave absorption of the materials.

Despite the $R L_{\min }$ and best effective absorbing bandwidth $(\mathrm{EAB},<-10 \mathrm{~dB})$ of $-13.9 \mathrm{~dB}$ and $0.87 \mathrm{GHz}$, respectively, occurring for the $7 \mathrm{wt} \%$ SG sample, its overall absorption performance is not as satisfactory as enough. And further increasing the SG content to $8 \mathrm{wt} \%$ deteriorates the microwave absorption ability of the composite, with a $R L_{\min }$ value of $-5.5 \mathrm{~dB}$. This is attributed to the impedance mismatch caused by the high dielectric constant of the composites. Excellent absorption materials should have, apart from a great loss ability for electromagnetic waves, a good impedance matching characteristic to reduce the reflection of electromagnetic waves on the surface of the material [65]. The ability of reflecting electromagnetic waves and the impedance matching characteristic of a material can be expressed by reflection coefficient $\Gamma$ [71]:

$$
\Gamma=\left|\left(Z_{\text {in }}-Z_{0}\right) /\left(Z_{\text {in }}+Z_{0}\right)\right|
$$

A low $\Gamma$ value supports a good impedance matching, that is, more electromagnetic waves could enter the material. The free-space impedance $Z_{0}$ value is fixed at 1 , and thus, it can be speculated from Eq. (11) that a low $\Gamma$ value, i.e., a well-matched impedance, can be obtained when the $Z_{\text {in }}$ value is close to 1 [72]. To obtain a deeper understanding of the absorption ability of the SG/AlN composites, the calculated $Z_{\text {in }}$ and $\Gamma$ values as a function of SG content are illustrated in Fig. 17. It can be seen from the $R L, Z_{\text {in }}$, and $\Gamma$ curves of the 7 and $8 \mathrm{wt} \%$ samples that at the frequency with the maximum $Z_{\text {in }}$ value (closest to 1 ), the materials exhibit the smallest $\Gamma$ value. This indicates the $R L_{\min }$ value can be achieved at the best impedance matching, i.e., when there is the least reflection of electromagnetic waves. Overall, the $Z_{\text {in }}$ values of all the SG/AIN composites are within in the range of $0-1$ in the X-band, and they increase first and then decrease as the SG content increases from 0 to $8 \mathrm{wt} \%$, reaching the maximum at $7 \mathrm{wt} \%$ SG. Conversely, the reflection coefficient $\Gamma$ of the composites gradually decreases as more $\mathrm{SG}$ is incorporated, attaining the minimum at $7 \mathrm{wt} \% \mathrm{SG}$ (0.14-0.44), indicating the best impedance matching in the composite with $7 \mathrm{wt} \% \mathrm{SG}$, which is in good agreement with its absorption ability. The above results indicate that good impedance is critical to the achievement of an excellent absorption property, which is highly dependent on the SG content. However, despite a high dielectric loss ability at a high SG content ( $8 \mathrm{wt} \%)$, the sample exhibits a weak absorption capability as a result of its poor impedance matching. On the whole, the AlN-based microwave attenuating composite ceramics, with its combined high thermal conductivity, improved dielectric loss, enhanced absorption ability, and low anisotropy, are developed by employing SG as attenuating agent.

\section{Conclusions}

In this work, SG/AlN microwave attenuating composite ceramics with 0 to $16 \mathrm{wt} \% \mathrm{SG}$ as the attenuating agent were prepared via hot-pressing sintering. The SG particles are homogeneously dispersed in the sintered 
bodies, displaying a 3D morphology and a negligible orientation alignment. The addition of SG impedes the sintering of the composites, and slightly influences on the growth of AlN grains. As the amount of SG added increases, the strength of the composites decreases monotonously, whereas the toughness initially increases and then decreases, with the maximum at $3.8 \mathrm{MPa} \cdot \mathrm{m}^{1 / 2}$ for the composite with $4 \mathrm{wt} \% \mathrm{SG}$, demonstrating a moderate toughening effect. Despite the significant decrease in the thermal conductivity with SG addition, the SG/AlN composites exhibit a relatively higher thermal conductivity compared to other composites with non-spherical attenuating agents. The enhanced polarization loss, conduction loss, and mini-capacitor effect with the addition of SG (0-8 wt \%) significantly improve the dielectric constant and loss (0.004-0.008 to $0.46-0.59$ ) of the composites within the frequency range of $8.2-12.4 \mathrm{GHz}$. The absorption ability is enhanced as SG is added, with composite with $7 \mathrm{wt} \%$ SG having the best absorption performance with a $R L_{\text {min }}$ of $-13.9 \mathrm{~dB}$ at $12.4 \mathrm{GHz}$ and a wide $\mathrm{EAB}$ $(0.87 \mathrm{GHz})$ at $7 \mathrm{wt} \%$ composite. In summary, the as-prepared SG/AIN composites are promising low anisotropic and highly thermally conductive attenuating materials.

\section{Acknowledgements}

This work was financially supported by the Priority Academic Program Development of Jiangsu Higher Education Institutions, the Postgraduate Research \& Practice Innovation Program of Jiangsu Province (KYCX20_0990), Qing Lan Project, the Program for Changjiang Scholars, Innovative Research Team in University (IRT1146 and IRT15R35), and the Top-notch Academic Programs Project of Jiangsu Higher Education Institutions (TAPP, PPZY2015B128).

\section{References}

[1] Zang XR, Lu YP. Preparation and dielectric properties at high frequency of AlN-based composited ceramic. J Mater Sci: Mater Electron 2020, 31: 2826-2832.

[2] Chen CF, Perisse ME, Ramirez AF, et al. Effect of grain boundary phase on the thermal conductivity of aluminium nitride ceramics. J Mater Sci 1994, 29: 1595-1600.

[3] Mikijelj B, Abe DK, Hutcheon R. AlN-based lossy ceramics for high average power microwave devices: Performance-property correlation. J Eur Ceram Soc 2003, 23: 2705-2709.
[4] Calame JP, Abe DK, Levush B, et al. Variable temperature measurements of the complex dielectric permittivity of lossy AlN-SiC composites from 26.5-40 GHz. J Appl Phys 2001, 89: 5618-5621.

[5] Chen YM, Pang L, Li Y, et al. Ultra-thin and highly flexible cellulose nanofiber/silver nanowire conductive paper for effective electromagnetic interference shielding. Compos Part A: Appl Sci Manuf 2020, 135: 105960.

[6] Green M, Chen XB. Recent progress of nanomaterials for microwave absorption. J Materiomics 2019, 5: 503-541.

[7] Simsek ING, Nistal A, García E, et al. The effect of graphene nanoplatelets on the thermal and electrical properties of aluminum nitride ceramics. J Eur Ceram Soc 2017, 37: 3721-3729.

[8] Yun C, Feng YB, Qiu T, et al. Mechanical, electrical, and thermal properties of graphene nanosheet/aluminum nitride composites. Ceram Int 2015, 41: 8643-8649.

[9] Chakravarty A, Singh R, Roy S, et al. Aluminum nitride-single walled carbon nanotube nanocomposite with superior electrical and thermal conductivities. J Am Ceram Soc 2017, 100: 3360-3364.

[10] Gu JL, Sang LL, Pan B, et al. Thermal conductivity and high-frequency dielectric properties of pressureless sintered SiC-AlN multiphase ceramics. Materials 2018, 11: 969.

[11] Li PW, Wang CB, Liu HX, et al. Structural, thermal and dielectric properties of AlN-SiC composites fabricated by plasma activated sintering. Adv Appl Ceram 2019, 118: 313-320.

[12] Min DD. Enhanced microwave absorption performance of double-layer absorbers containing $\mathrm{BaFe}_{12} \mathrm{O}_{19}$ ferrite and graphite nanosheet composites. J Electron Mater 2020, 49: 819-825.

[13] Meng R, Zhang T, Yu HJ, et al. A facile coprecipitation method to synthesize $\mathrm{Fe}_{x} \mathrm{O}_{y} / \mathrm{Fe}$ decorated graphite sheets with enhanced microwave absorption properties. Nanotechnology 2019, 30: 185704.

[14] Qiu J, Qiu TT. Fabrication and microwave absorption properties of magnetite nanoparticle-carbon nanotubehollow carbon fiber composites. Carbon 2015, 81: 20-28.

[15] Gupta KK, Abbas SM, Abhyankar AC. Carbon black/polyurethane nanocomposite-coated fabric for microwave attenuation in $\mathrm{X} \& \mathrm{Ku}$-band $(8-18 \mathrm{GHz})$ frequency range. $J$ Ind Text 2016, 46: 510-529.

[16] Kim JB, Lee SK, Kim CG. Comparison study on the effect of carbon nano materials for single-layer microwave absorbers in X-band. Compos Sci Technol 2008, 68: 2909-2916.

[17] Meng FB, Wang HG, Huang F, et al. Graphene-based microwave absorbing composites: A review and prospective. Compos Part B: Eng 2018, 137: 260-277.

[18] Liao XJ, Ye W, Chen LL, et al. Flexible hdC-G reinforced polyimide composites with high dielectric permittivity. Compos Part A: Appl Sci Manuf 2017, 101: 50-58.

[19] Xu WH, Ding YC, Yu Y, et al. Highly foldable 
PANi@CNTs/PU dielectric composites toward thin-film capacitor application. Mater Lett 2017, 192: 25-28.

[20] Liang HL, Wang CP, Huo YL, et al. AlN/CNT composites ceramics by spark plasma sintering. Key Eng Mater 2014, 602-603: 570-573.

[21] Shen Y, Zhang H, Yang AM, et al. Outgassing property of carbon nanotube cathode with intense pulsed emission. Acta Phys Sinica 2012, 61: 103-109. (in Chinese)

[22] Shen Y, Zhang H, Liu XG, et al. Outgassing mass spectrum analysis with intense pulsed emission of carbon nanotube cathode. Acta Phys Sinica 2011, 60: 1-8. (in Chinese)

[23] Yin R, Zhang YB, Zhao W, et al. Graphene platelets/aluminium nitride metacomposites with double percolation property of thermal and electrical conductivity. J Eur Ceram Soc 2018, 38: 4701-4706.

[24] Chen JK, Wang LM, Gui XC, et al. Strong anisotropy in thermoelectric properties of CNT/PANI composites. Carbon 2017, 114: 1-7.

[25] Zhang XY, Shi ZQ, Zhang X, et al. Three dimensional AlN skeleton-reinforced highly oriented graphite flake composites with excellent mechanical and thermophysical properties. Carbon 2018, 131: 94-101.

[26] Fan YZ, Yang HB, Li MH, et al. Evaluation of the microwave absorption property of flake graphite. Mater Chem Phys 2009, 115: 696-698.

[27] Yuan GM, Li XK, Dong ZJ, et al. Graphite blocks with preferred orientation and high thermal conductivity. Carbon 2012, 50: 175-182.

[28] Zheng WG, Wong SC. Electrical conductivity and dielectric properties of PMMA/expanded graphite composites. Compos Sci Technol 2003, 63: 225-235.

[29] He FA, Lau S, Chan HL, et al. High dielectric permittivity and low percolation threshold in nanocomposites based on poly(vinylidene fluoride) and exfoliated graphite nanoplates. Adv Mater 2009, 21: 710-715.

[30] Wang P, Cheng LF, Zhang YN, et al. Electrospinning of graphite/SiC hybrid nanowires with tunable dielectric and microwave absorption characteristics. Compos Part A: Appl Sci Manuf 2018, 104: 68-80.

[31] Du YC, Liu T, Yu B, et al. The electromagnetic properties and microwave absorption of mesoporous carbon. Mater Chem Phys 2012, 135: 884-891.

[32] Torğut G, Biryan F, Demirelli K. Effect of graphite particle fillers on dielectric and conductivity properties of poly(NIPAM-co-HEMA). Bull Mater Sci 2019, 42: 244.

[33] Sun MY, Bai YH, Li MX, et al. Improved toughness and electromagnetic shielding-effectiveness for graphite-doped SiC ceramics with a net-like structure. J Eur Ceram Soc 2018, 38: 5271-5281.

[34] Zhang Y, He PG, Yuan JK, et al. Effects of graphite on the mechanical and microwave absorption properties of geopolymer based composites. Ceram Int 2017, 43: 2325-2332.

[35] Kováčik J, Emmer. Cross property connection between the electric and the thermal conductivities of copper graphite composites. Int J Eng Sci 2019, 144: 103130.

[36] Marinopoulos AG, Reining L, Olevano V, et al. Anisotropy and interplane interactions in the dielectric response of graphite. Phys Rev Lett 2002, 89: 076402.

[37] Zeng FK, Xue C, Ma HB, et al. High thermal conductivity and anisotropy values of aligned graphite flakes/copper foil composites. Materials 2019, 13: 46.

[38] Li WJ, Liu Y, Wu GH. Preparation of graphite flakes/Al with preferred orientation and high thermal conductivity by squeeze casting. Carbon 2015, 95: 545-551.

[39] Yoshio M, Wang HY, Fukuda K. Spherical carbon-coated natural graphite as a lithium-ion battery-anode material. Angew Chem Int Ed 2003, 42: 4203-4206.

[40] Wu YS, Wang YH, Lee YH. Performance enhancement of spherical natural graphite by phenol resin in lithium ion batteries. J Alloys Compd 2006, 426: 218-222.

[41] Li M, Fang ZN, Wang SK, et al. Thermal conductivity enhancement and heat transport mechanism of carbon fiber z-pin graphite composite structures. Compos Part B: Eng 2019, 172: 603-611.

[42] Huang D, Tian ZB, Cui W, et al. Effects of $\mathrm{Y}_{2} \mathrm{O}_{3}$ and yttrium aluminates as sintering additives on the thermal conductivity of AlN ceramic substrates. Ceram Int 2018, 44: 20556-20559.

[43] Nakano H, Watari K, Hayashi H, et al. Microstructural characterization of high-thermal-conductivity aluminum nitride ceramic. J Am Ceram Soc 2004, 85: 3093-3095.

[44] Narang V, Korakakis D, Seehra MS. Electronic state of Er in sputtered AlN: Er films determined by magnetic measurements. J Appl Phys 2014, 116: 213911.

[45] Jiang SH, Cheong JY, Nam JS, et al. High-density fibrous polyimide sponges with superior mechanical and thermal properties. ACS Appl Mater Interfaces 2020, 12: 19006-19014.

[46] Wang F, Chen L, Li HL, et al. N-doped honeycomb-like porous carbon towards high-performance supercapacitor. Chin Chem Lett 2020, 31: 1986-1990.

[47] Yan DF, Guo L, Xie C, et al. N, P-dual doped carbon with trace $\mathrm{Co}$ and rich edge sites as highly efficient electrocatalyst for oxygen reduction reaction. Sci China Mater 2018, 61: 679-685.

[48] Zhao CL, Wu YX, Liang HL, et al. N-doped graphene and $\mathrm{TiO}_{2}$ supported manganese and cerium oxides on low-temperature selective catalytic reduction of $\mathrm{NO}_{x}$ with $\mathrm{NH}_{3}$. J Adv Ceram 2018, 7: 197-206.

[49] Zhou SZ, Zhou GY, Jiang SH, et al. Flexible and refractory tantalum carbide-carbon electrospun nanofibers with high modulus and electric conductivity. Mater Lett 2017, 200: 97-100.

[50] Kuang BY, Song WL, Ning MQ, et al. Chemical reduction dependent dielectric properties and dielectric loss mechanism of reduced graphene oxide. Carbon 2018, 127: 209-217.

[51] Yu JJ, Liu SW, Duan GG, et al. Dense and thin coating of gel polymer electrolyte on sulfur cathode toward high performance Li-sulfur battery. Compos Commun 2020, 19: 
239-245.

[52] Duan GG, Liu SW, Jiang SH, et al. High-performance polyamide-imide films and electrospun aligned nanofibers from an amide-containing diamine. J Mater Sci 2019, 54: 6719-6727.

[53] Cho WS, Cho MW, Lee JH, et al. Effects of h-BN additive on the microstructure and mechanical properties of AlN-based machinable ceramics. Mater Sci Eng: A 2006, 418: $61-67$.

[54] Chen C, Pan LM, Li XY, et al. Mechanical and thermal properties of graphene nanosheets/magnesia composites. Ceram Int 2017, 43: 10377-10385.

[55] Wang XL, He XB, Zhang R, et al. Interface and properties of copper matrix composites reinforced with $\mathrm{TiC}$ coated spherical graphite. Mater Res Express 2019, 6: 116307.

[56] Schlichting KW, Padture NP, Klemens PG. Thermal conductivity of dense and porous yttria-stabilized zirconia. J Mater Sci 2001, 36: 3003-3010.

[57] Landon M, Thevenot F. Thermal conductivity of SiC-AlN ceramic materials. J Eur Ceram Soc 1991, 8: 271-277.

[58] Rutkowski P, Kata D, Jankowski K, et al. Thermal properties of hot-pressed aluminum nitride-graphene composites. $J$ Therm Anal Calorim 2016, 124: 93-100.

[59] Baskut S, Cinar A, Turan S. Directional properties and microstructures of spark plasma sintered aluminum nitride containing graphene platelets. J Eur Ceram Soc 2017, 37: 3759-3772.

[60] Ren LL, Zeng XL, Sun R, et al. Spray-assisted assembled spherical boron nitride as fillers for polymers with enhanced thermally conductivity. Chem Eng J 2019, 370: 166-175.

[61] Wang JJ, Yi XS. Effects of interfacial thermal barrier resistance and particle shape and size on the thermal conductivity of AlN/PI composites. Compos Sci Technol 2004, 64: 1623-1628.

[62] Guo X, Feng YR, Lin X, et al. The dielectric and microwave absorption properties of polymer-derived $\mathrm{SiCN}$ ceramics. J Eur Ceram Soc 2018, 38: 1327-1333.

[63] Zhou L, Cui S, Zhai Y, et al. Dielectric and microwave absorption properties of plasma sprayed $\mathrm{Cr} / \mathrm{Al}_{2} \mathrm{O}_{3}$ composite coatings. Ceram Int 2015, 41: 14908-14914.

[64] Li W, Li XC, Gong W, et al. Construction of multiple heterogeneous interface and its effect on microwave absorption of SiBCN ceramics. Ceram Int 2020, 46: 7823-7832.
[65] Qin M, Lan D, Wu GL, et al. Sodium citrate assisted hydrothermal synthesis of nickel cobaltate absorbers with tunable morphology and complex dielectric parameters toward efficient electromagnetic wave absorption. Appl Surf Sci 2020, 504: 144480.

[66] Long L, Xu JX, Luo H, et al. Dielectric response and electromagnetic wave absorption of novel macroporous short carbon fibers/mullite composites. J Am Ceram Soc 2020, 103: 6869-6880.

[67] Calame JP, Abe DK, Levush B, et al. Broadband complex dielectric permittivity of porous aluminum silicate-pyrolytic carbon composites. J Am Ceram Soc 2005, 88: 2133-2142.

[68] Li XL, Yin XW, Song CQ, et al. Self-assembly core-shell graphene-bridged hollow MXenes spheres 3D foam with ultrahigh specific EM absorption performance. Adv Funct Mater 2018, 28: 1803938.

[69] Yu ZJ, Lv X, Mao KW, et al. Role of in situ formed free carbon on electromagnetic absorption properties of polymerderived SiC ceramics. $J$ Adv Ceram 2020, 9: 617-628.

[70] Liu JL, Liang HS, Wu HJ. Hierarchical flower-like $\mathrm{Fe}_{3} \mathrm{O}_{4} / \mathrm{MoS}_{2}$ composites for selective broadband electromagnetic wave absorption performance. Compos Part A: Appl Sci Manuf 2020, 130: 105760.

[71] Ye F, Zhang LT, Yin XW, et al. Dielectric and microwaveabsorption properties of $\mathrm{SiC}$ nanoparticle/SiBCN composite ceramics, J Eur Ceram Soc 2014, 34: 205-215.

[72] Lou ZC, Li R, Wang P, et al. Phenolic foam-derived magnetic carbon foams (MCFs) with tunable electromagnetic wave absorption behavior. Chem Eng J 2020, 391: 123571.

Open Access This article is licensed under a Creative Commons Attribution 4.0 International License, which permits use, sharing, adaptation, distribution and reproduction in any medium or format, as long as you give appropriate credit to the original author(s) and the source, provide a link to the Creative Commons licence, and indicate if changes were made.

The images or other third party material in this article are included in the article's Creative Commons licence, unless indicated otherwise in a credit line to the material. If material is not included in the article's Creative Commons licence and your intended use is not permitted by statutory regulation or exceeds the permitted use, you will need to obtain permission directly from the copyright holder.

To view a copy of this licence, visit http://creativecommons. org/licenses/by/4.0/. 